This report was prepared as an account of work sponsored by an agency of the United States Government. Neither the United States Government nor any agency thereof, nor any of their employees, makes any warranty, express or implied, or assumes any legal liability or responsibility for the accuracy, completeness, or usefulness of any information, apparatus, product, or process disclosed, or represents that its use would not infringe privately owned rights. Reference herein to any specific commercial product, process, or service by trade name, trademark, manufacturer, or otherwise does not necessarily constitute or imply its endorsement, recommendation, or favoring by the United States Government or any agency thereof. The views and opinions of authors expressed herein do not necessarily state or reflect those of the United States Government or any agency thereof.

\title{
The Future Steelmaking Industry And Its Technologies
}

\author{
R. J. Fruehan \\ H. W. Paxton \\ F. Giarratani \\ L. Lave
}

Completed December 1994

Published January 1995

\section{Sloan Steel Industry Competitiveness Study Carnegie Mellon University and the University of Pittsburgh Pittsburgh, Pennsylvania}

Prepared for Lockheed Idaho Technologies Company Under Subcontract No. C94-170736 and for the

U.S. Department of Energy

Office of Industrial Technologies (OIT)

Under DOE Idaho Field Office

Contract DE-AC07-94ID13223

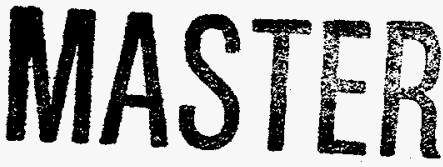




\section{DISCLAIMER}

Portions of this document may be illegible in electronic image products. Images are produced from the best available original document. 


\section{TABLE OF CONTENTS}

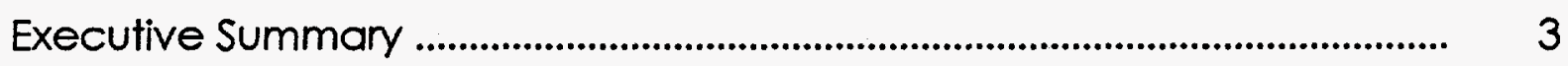

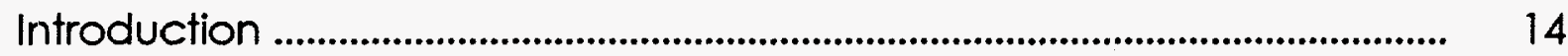

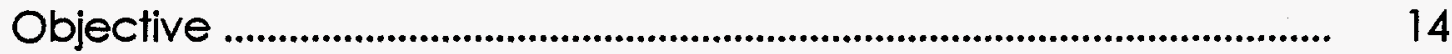

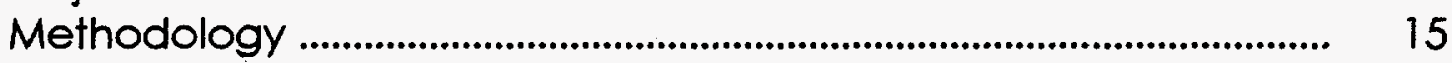

Importance of Industry ............................................................................... 16

Past and Present Drivers ....................................................................................... 18

Competitive Factors ........................................................................... 19

International Competition ........................................................................ 31

Environmental Concerns and Regulations .......................................... 41

Technological Developments .................................................................. 45

Capital Requirements ............................................................................. 48

Scrap Price and Availability ............................................................... 51

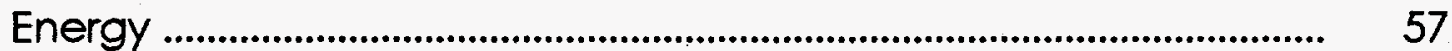

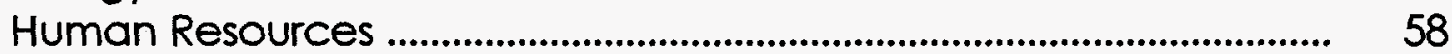

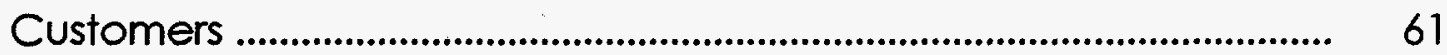

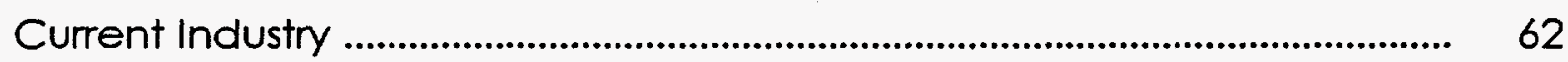

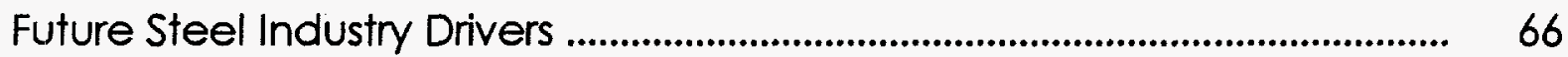

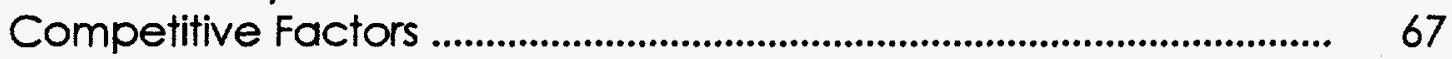

International Competition ...................................................................... 74

Environmental Concerns and Regulations ............................................. 78

Technological Drivers ................................................................................. 80

Capital Requirements ....................................................................... 82

Scrap and Scrap Substitutes .................................................................. 83

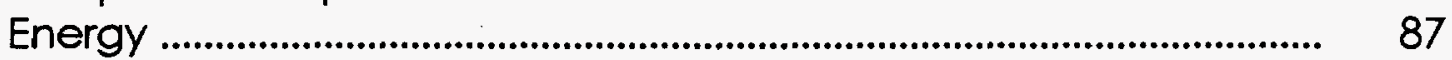

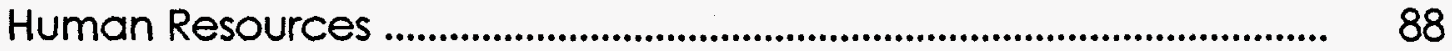

The Future Steelmaking Industry ............................................................................. 90

Prediction of Future Industry Characteristics ............................................. 90

Future Steelmaking Technologies ........................................................... 95

Challenges and Opportunities for Future Steelmaking ...................... 105

Priorities and Concluding Remarks ............................................................... 124 


\section{A VISION OF THE FUTURE STEEL INDUSTRY}

\section{EXECUTIVE SUMMARY}

The objective of this report is to develop a vision of the future steelmaking industry including its general characteristics and technologies. In addition, the technical obstacles and research and development opportunities for commercialization of these technologies are identified. The report is being prepared by the Sloan Steel Industry Competitiveness Study with extensive input from the industry. Industry input has been through AISI (American Iron and Steel Institute), SMA (Steel Manufacturers Association) and contacts with individual company executives and technical leaders.

The report identifies the major industry drivers which will influence technological developments in the industry for the next 5-25 years. Initially, the role of past drivers in shaping the current industry was examined to help understand the future developments. Whereas this report concentrates on future technologies other major factors such as national and international competition, human resource management and capital concerns are examined to determine their influence on the future industry. The future industry vision does not specify specific technologies but rather their general characteristics. Finally, the technical obstacles and the corresponding research and development required for commercialization are detailed.

The major industry drivers and their impact are summarized below:

Domestic Competitive Factors: Poor economic performance in the past hindered technology implementation and will continue to be a major factor. The automotive market will be threatened by competing materials but there are opportunities in home construction for sizable growth.

International Competition: Whereas, the US industry has reduced over capacity to place supply in balance with demand, Europe and Japan for political or 


\section{SUMMARY}

social reasons are now only very slowly reducing unneeded capacity. With the new trade agreements, pressure from imports will continue, however if there is reasonable fair trade they will be at acceptable levels.

Capital Requirements: The steel industry, in particular, the front or hot end of the integrated process, is highly capital intensive. It is difficult to justify new investments unless technologies are developed which reduce capital requirements.

Environmental Concerns: Environmental concerns and regulations will require technologies with reduced emissions. Also, recycling of plant wastes will be required.

Previous Technology Developments: Technology developments which are currently being implemented, such as thin slab casting, will dictate changes in other parts of the manufacturing system.

Scrap Availability and Substitutes: Scrap price and availability will influence the industry structure and require technological developments to improve scrap quality and reduce the capital and production costs for scrap substitutes.

Energy: Previous reductions in energy consumption were primarily due to the implementation of continuous casting and other yield improvements; further improvements will be more difficult. Processes which are flexible with respect to energy source will be developed.

Human Resources: Technologies which are less labor intensive will be required. Furthermore, new facilities must be flexible in the use of labor and employee compensation.

Customers: Customer demands with respect to quality and quick and reliable delivery will continue to be a major driver. 


\section{SUMMARY}

Whereas the industry has made significant improvements in its competitiveness it faces enormous challenges in order to maintain or improve its position. Due primarily to environmental concerns, capital reduction requirements, competitive materials and the need for improved charge materials new technologies are imperative.

FUTURE - INDUSTRY

The steel industry will insure that steel will be the material of choice in the future. Steel will be an excellent value as a material with a combination of superior properties, which is recyclable, used easily in manufacturing and available at a relatively low price. Processes will be developed which will be more flexible and continuous and eliminate some of the current process steps. The industry will be profitable, environmentally responsible and internationally competitive.

The future industry's general characteristics were identified.

- The industry will play a major role in the US economy, have an improved economic performance, and be the low cost quality producer for its market. Imports will continue and possibly shift from traditional areas (Europe and Japan) to developing economies, but if there is fair trade they will be at acceptable levels.

- Recycling of obsolete scrap and solid process wastes will increase and processes will be more environmentally friendly. However, emission standards will require huge capital investments and lead to the closing of many facilities.

- Due to environmental concerns more ore based plants may stop coke production and possibly even steelmaking and simply import slabs, ("deintegration"). Conversely some scrap based producers will integrate back into direct reduced iron production and forward into complex finishing. As a result, the lines between the two traditional industry segments will be blurred. 


\section{SUMMARY}

- New technologies will be more flexible with regards to production and energy and continuous in nature. Processes will be developed which will combine some of the existing processes, e.g., direct ironmaking will eliminate cokemaking and near net shape casting most of the hot rolling.

They will require more flexible use of labor; education and training will be more critical.

- Industry partnering with customers will continue to grow not only with regards to steel quality but also in effective use and product designs with steel.

No single manufacturing system will be best for the production of steel, it will depend on production requirements and the plant's market. The plants will range from traditional large integrated facilities for production of the highest quality steels to traditional electric furnace melting of obsolete scrap for bars. However, two new types of plants will develop, Mini-Integrated and Advanced Scrap/Alternate Iron based plants, which will produce flat rolled, special bars and shapes.

\section{FUTURE STEELMAKING TECHNOLOGIES}

The future technologies will eliminate some unit processes (e.g., cokemaking), make use of in-plant solid wastes as raw materials, be more flexible in energy sources and the overall process will approach continuous flow. The industry will develop products with superior properties and which can be easily recycled.

Scrap based production will continue to grow over the next five to ten years. However, due to product requirements, economic factors, and since scrap alone cannot provide for all the steel required, an equilibrium between ore and scrap based production will develop. This equilibrium will depend on many factors and it is difficult to predict exactly where it will be but it should be close to being equally balanced. Some ore based production will be in the form of DRI or similar products. 


\section{SUMMARY}

Ironmaking: Ironmaking developments will occur by evolutionary changes in the current processes, new direct ironmaking processes using coal and possible revolutionary processes. Coal injection will increase to 500 pounds while coke rates decrease to 500 pounds per ton of hot metal (THM). Beyond 500 pounds of coal, ore injection and top gas circulation may be required. Burden preparation and distribution will improve and for specific economic conditions more scrap or reduced iron and natural gas will be used.

Processes such as COREX and AISI Direct Ironmaking will be implemented at a relatively slow rate (less than 5 million tons per year by 2010) and will require special circumstances to warrant the investment. For example, COREX requires the economic use of the excess gas and the others will be used for small production requirements ( $<0.5 \mathrm{mtpy}$ ) or for special feeds such as waste oxides. Revolutionary developments, yet to be clearly defined, should not be rules out (e.g., low temperature reduction followed by a smelting process).

Refining: Developments in refining and steelmaking are less critical and will have less impact than those in other areas. Possibilities include continuous steelmaking, ladle processes for nitrogen and phosphorus, and reduced maintenance and refractory costs.

Charge Materials: In order for traditional scrap based processes to expand further into higher quality steels, developments must occur to improve charge materials. Processes to remove residuals from obsolete scrap and to produce scrap substitutes, in particular, a coal based process with lower capital cost will be needed.

Flexible and Efficient Melting: Energy efficiency and productivity will improve by effective scrap preheating. Processes which use both electrical and fossil fuels effectively will be used. 


\section{SUMMARY}

Solidification Processes: No single casting process will be satisfactory for all of the industry needs. Conventional, thin slab, and strip casting will be used depending on production and market requirements. Processes which cast closer to the final shape for constructional shapes will be more widely used.

Finishing and Products: The industry is capable of making steel of well controlled composition and free of defects; future gains will occur but will be increasingly difficult. There will be process coupling, compact annealing processes, new coatings and methods of application, and evolutionary changes in new product development.

Process Linkage and Global Optimization: Delivery times, energy consumption and costs will be decreased by direct process linkage and global optimization of the manufacturing system.

\section{CHALLENGES AND OPPORTUNITIES FOR THE FUTURE INDUSTRY}

Before examining the technical obstacles facing the future industry the economic prerequisites, technical capabilities and international developments which will influence its development were examined. For any technology to be developed the industry must be profitable and the new technology must satisfy an industry driver and give a reasonable return on investment. Due to the risk associated with the high capital costs for commercialization development of these technologies will require special circumstances and may be done on a collaborative basis.

The US industry's research and development capabilities have been greatly reduced and are considerably less than its international competitors (less than one third). By being more focused and directly involved with plants and customers it is reasonably effective but would be stretched to carry out major developments on an 


\section{SUMMARY}

individual company basis. Major international developments which must be carefully monitored before making investments in a specific technological development. The report briefly examines developments in direct ironmaking, strip casting, scrap substitutes and recycling.

\section{SPECIFIC AREAS FOR RESEARCH AND DEVELOPMENT REQUIRED FOR COMMERCIALIZATION}

\section{Ironmaking}

- A process which uses coal directly and is less capital intensive than the blast furnace. Specifically this will require research to:

- use volatiles more effectively

- improve metal containment

- achieve higher post combustion

- improve hot metal desulfurization

- improve injection of ores or waste oxides

- develop sensors for foam height and for metal and slag chemistry

- Blast furnace optimization

- improve use of injectants in particular burden distribution for larger gas through puts

- examine recirculation of top gas and ore injection

- improve process models, instrumentation and sensors

- develop a low cost process to produce partially reduced iron feeds

\section{Steelmaking and Refining}

- Current Processes

- improve dynamic control and sensors

- improve refractories 


\section{SUMMARY}

- improve post combustion

- develop ladle processes to lower nitrogen and phosphorus

- A continuous refining process with lower capital cost compared to the current batch oxygen steelmaking process.

\section{Charge Materials}

- Scrap

- improve obsolete scrap preparation to reduce residuals

- develop processes to chemically remove residuals including zinc

- develop processes to economically use or dispose of shredder fluff

- develop improved methods of identifying radioactive material in scrap

- Scrap Alternatives

- develop a coal based process to produce direct reduced iron including sulfur removal

- develop gas based processes which are lower in capital and operating cost

The US should consider a major program to recycle more scrap effectively and insure adequate quantities of scrap substitutes.

\section{Improved Melting}

- develop new processes which effectively preheat scrap using off gases without the formation of dioxins.

- improve post combustion and processes to reduce emissions

- develop hybrid processes which are flexible in their energy source

- One of the most pressing needs is to develop processes which minimize electric furnace dust generation or can effectively make use of them for producing iron and zinc ("man made resources"). 


\section{SUMMARY}

\section{Solidification Processes}

- Conventional and Thin Slab

- develop mold fluxes with no environmental concerns

- develop metal delivery systems which reduce turbulence, slag entrainment and clogging

- Strip Casting

- improve edge containment

- improve metal delivery for improved control and surface quality

- improve roll design to insure stable dimensions and improve surface quality

- In general, develop control models and expert systems to predict structure and properties and diagnose defects.

\section{Environmental Technologies}

- Reduce in-plant solid wastes by using them as "man made resources"

- develop processes to use blast furnace and BOF dusts to produce iron

- develop processes which minimize slag and processes which use these for production of other materials

- Emissions

- develop new technologies to treat large quantities of water for reuse

- carry out risk analysis of toxic emissions

- Develop methods of assessing and carrying out site clean up

\section{Finishing and Products}

- develop processes and steel compositions which will permit compact annealing

- develop a compact low capital cost continuous annealing process

- improve coatings and application processes, in particular, products 


\section{SUMMARY}

which can be effectively recycled.

- couple processes to approach continuous flow which will require techniques to measure directly, or by surrogates, grain size, yield stress, etc.

- develop processes which can produce product properties which are currently obtained through steel chemistry

- develop processes which improve the surface quality of directly cast sheet

- develop products and processes which make the steel chemistry requirements less sensitive to residuals

\section{General Areas}

- develop compact processes for production of normal quality oxygen and low cost processes for less pure oxygen

- improve refractories and metal containment systems for specific systems

- develop expert systems for maintenance and defect diagnosis

- improve training of current workers and education of future workers

\section{PRIORITIES AND CONCLUDING REMARKS}

The most critical long term technological challenges identified with the aid of the industry included:

- Commercialization of a direct ironmaking process eliminating the capital and environmental concerns.

- Commercialization of processes to recycle in-plant wastes, in particular, EAF, BOF, and blast furnace dusts.

- Develop processes to improve charge materials to the EAF including reducing residuals in scrap and a coal based direct reduction process. 


\section{SUMMARY}

- Develop a steelmaking process which may include flexibility in feed materials and energy source and effective scrap preheating.

- The development of a range of casting processes for near net shapes, with an understanding of the factors necessary to produce desired properties without the large hot deformations common to existing technology.

- Develop processes which approach continuous flow and carryout global optimization of the steelmaking system.

- Work on improvements to current rolling equipment and to sensors and process control to produce continuing viable improvements in property combinations to keep steels competitive and cost effective.

- Further improvements in coating technology, and its control, to tailor products to applications.

- A continuing emphasis on customer anticipation and satisfaction, ranging from development of realistic simulated service tests to cooperation in developing customer-specific opportunities in forming and joining.

The development of these technologies will help insure that steel will be the material of choice and the steel industry processes are more continuous, flexible, economic and consistent with the national environmental goals. 


\section{VISION OF THE FUTURE STEELMAKING INDUSTRY}

\section{INTRODUCTION}

\section{OBJECTIVE}

The objective of this report is to develop a vision of the future steelmaking industry, identify its technologies, and the technical obstacles which must be overcome to achieve this vision. This is accomplished by examining how past and present drivers shaped the current industry, identifying current and future drivers and how these drivers will influence future steelmaking processes. A vision of the future industry's characteristics and its technologies is presented and critical research, development and opportunities for commercialization of these processes are identified.

The industry vision is for 5 to 25 years out (2000-2020), however, some aspects of the research and development plan should commence in the near term. This report's customers are the steel industry, government agencies, and other stake holders in the future steel industry. Therefore, the report will contain general observations or conclusions to help those not intimately involved in the industry and more specific details for those more familiar with the industry. The industry must be in general agreement with the vision for it to have creditability.

This report primarily deals with a vision of future technologies and barriers to their development and commercialization. However, it considers several important factors which influence the technologies, e.g., economics including international trade, energy, capital, human resources, and environmental regulations. 


\section{INTRODUCTION METHODOLOGY}

- A team of economic and technology experts associated with the Sloan Steel Industry Competitiveness Study from Carnegie Mellon University and the University of Pittsburgh prepared the report. The Sloan Study is a six year program sponsored by the Alfred P. Sloan Foundation and the international steel industry aimed at examining the critical issues for competitiveness.

- The team relied heavily on industry experts specifically for developing the Vision as well as the experience gained from the Sloan Study.

- The team coordinated their activities with the American Iron and Steel Institute (AISI) and the Steel Manufacturers Association (SMA). Presentations of preliminary ideas were made and helpful discussions were held with committees, officers and staff of these organizations.

- A preliminary report was developed and circulated to the industry, government and other interested parties.

- A meeting was held with industry leaders in late 1994 to discuss this report, the vision of the future industry and a list of technological challenges. This was done to insure that industry takes "ownership" of this vision and research objectives as their own. Based on their input, the report was extensively revised. This may be followed by a general workshop which will include all interested stake holders. There are some redundancies in the report to be sure that each section stands on its own. 


\section{INTRODUCTION}

\section{The US Steel Industry's Status and Contributions to the Economy}

The US steel industry was in critical economic condition in the early 1980's. Several major companies were in or on the verge of bankruptcy. Compared to its international competitors it had low productivity, low quality products and high costs. In the past eight years the industry has restructured itself by closing obsolete plants, making strategic investments to improve quality and productivity, and improving management and human resource practices. The industry has made a remarkable recovery and it is considered by many international experts to be the most efficient steel producer in the world. It is the low cost producer for the US market, has improved labor productivity by over $250 \%$, has significantly decreased energy consumption and has many world class quality products. The scrap based electric furnace producers, "minimills", are considered by some to be world leaders in efficiency, in the flexible use and compensation of employees, technology implementation and entering new markets.

Despite these vast improvements the industry must face economic and technological challenges to remain competitive. Imports have increased since 1991, profitability remains low, therefore, limiting investment, and high labor costs and environmental and government policies will continue to force the industry to adapt to remain competitive. 


\section{INTRODUCTION}

\section{Importance of the Steel Industry to the Economy}

- The US industry produced 98 million tons of liquid steel in 1993, an increase of $5 \%$ over 1992 . Capacity utilization increased from $79 \%$ to $86 \%$ from 1992 to 1993 partially due to a decrease of $3 \%$ in capacity. In 1994 capacity utilization is over $90 \%$.

- Several new plants are being built or planned which could add up to 10 to 15 million tons of highly efficient production capacity by the year 2000 .

- Sales of all steels rose to $\$ 43$ billion, with carbon and low alloy steel representing about $90 \%$ of sales. Sales could rise to over $\$ 50$ billion in 1994 or 1995 from the combination of volume, price and product mix.

- Direct employment is about 225,000, down from 500,000 in 1983 primarily due to improved productivity. Production workers are about 182,000 with earnings $50 \%$ higher than for the average of all manufacturing.

- The steel industry is vital to many manufacturing industries including automotive, construction, defense, appliances, etc.

- The industry uses 1.5 to 1.8 quads of energy per year depending on production. The industry has made great strides in reducing energy consumption. Since 1975 energy consumption per ton of steel shipped has decreased by $45 \%$; in 1993 alone there was a 9\% decrease.

- The decrease in energy has resulted from the implementation of continuous casting, improved production practices leading to increased yields and general implementation of energy efficient practices.

- The steel industry is a major recycler. About $65 \%$ of new steel products are made from recycled scrap. 


\section{PAST AND PRESENT INDUSTRY DRIVING FORCES}

The Current Steel Industry was the Result of Driving Forces including Competitive Factors, International Competition, Government Regulation, Customer Needs, Capital Requirements, Scrap Availability and Human Resources. The Past Drivers and their Effect on the Current Industry are examined to Provide a Perspective and Help Better Define the Future Industry.

For the present purposes the major past and present driving forces have been grouped into the following nine areas:

Competitiveness: The major competitive factors including Steel Consumption, Overcapacity, Imports, Scrap Based Producers, Competing Materials and Economic Performance have had a major impact on the current industry.

International Competition: In addition to the impact of imports and the VRA's, the response of foreign competitors to the competitive factors are examined.

Environmental Concerns and Regulations: Environmental Regulation, CAFE Standards, Recycling and other government regulations helped shape the current industry.

Technological Changes: The effect of oxygen steelmaking, continuous casting, and advanced scrap melting have influenced the industry structure and efficiency and along with better finishing facilities have led to quality improvements.

Capital: The steel industry is a highly capital intensive industry and capital restraints and cost greatly influence technology decisions.

Scrap Price and Availability: The price and availability of scrap have greatly affected the structure, technologies and competitive features of the current industry.

Energy: The escalating cost of energy caused changes in technology and the distribution of products being produced.

Human Resources: Personnel costs represent from $10-25 \%$ of the cost of producing steel depending on the product and plant; therefore, technologies which reduce labor have been installed.

Customers: Customer demands and expectations have led to the installation of technologies to improve quality and service. 


\section{PAST AND PRESENT DRIVERS}

\section{COMPETITIVE FACTORS}

The U.S. steel industry has faced enormous competitive factors which have caused it to restructure. These factors included world and local overcapacity, aging facilities, significant imports, the growth of the scrap based minimill, and threats from competing materials. Over the last decade, drastic actions have permitted the major integrated mills to remain competitive.

OVERCAPACITY: For the last twenty years, there has been a $20-30 \%$ worldwide capacity for steel production and often an even greater discrepancy in the U.S. when imports were high. Over the last decade, about one third, mostly inefficient capacity, has been shut down in the U.S. giving a current utilization rate around $90 \%$ - probably as high as sustainable.

IMPORTS: World excess capacity and the strong dollar in the early and middle 1980 's allowed imports to reach as high as $26.5 \%$ of consumption in 1984 . Increasing efficiency and cost-cutting led to lower dollars/ton in U.S. prices and coupled with a weaker dollar made sales in the U.S. less attractive to many offshore firms, and in 1992 , the import percentage was down to $18.0 \%$.

SCRAP BASED PRODUCTION: From a modest beginning on small quantities of the least complex products, scrap based electric furnace production has grown to about $38 \%$ with some of this in the middle of the product quality range and with very competitive prices. The integrated mills have reacted by concentrating on higher quality products and a program of rapidly increasing product quality and value. 


\section{PAST AND PRESENT DRIVERS COMPETITIVE FACTORS}

COMPETITIVE MATERIALS: Starting some 20 years ago, steel lost the carbonated beverage container market to aluminum (about 3 million tons/year at the current volume of 100 billion cans per year). The fiercely competitive automobile market has lost some percentage to aluminum and plastics but much more tonnage to downsizing of the automobile. Construction remains active between steel, concrete, brick and stone, and wood; steel is not losing market share and may gain a little at the expense of wood.

ECONOMIC PERFORMANCE: These factors have led to a relatively poor economic performance in the past 20 years. Integrated steel makers in the United States sustained large losses during the restructuring of the early and mid-1980s, and their return to profitability was delayed by national recession in the early $1990 \mathrm{~s}$. In the period 1982-1992, integrated steel producers in the United States suffered losses in all but three years. These losses were enormous, reaching a maximum of over $\$ 4$ billion in 1986. In sharp contrast, non-integrated producers have sustained profits over a very long period of time. The rate of return on assets for non-integrated producers in the United States has been very good. Not only have these firms outperformed their domestic competition, but they have been more profitable than steelmakers in Japan.

The net result of these competitive driving forces was to reduce capital for new technologies while requiring quality and productivity improvements in order to remain competitive. The industry has responded by making strategic investments and optimizing existing processes, i.e., "doing more with less". 
PAST AND PRESENT DRIVERS

\section{COMPETITIVE FACTORS}

\section{OVERCAPACITY}

- World steel consumption grew between 2 and $3 \%$ per year from 1875 to 1975 , and has basically been flat for the last 20 years, although production in individual regions has changed.

- World production capacity on average has been $20-25 \%$ above consumption for over 30 years. This inefficient use has been largely due to various government initiatives intended to create or maintain employment in their own jurisdictions.

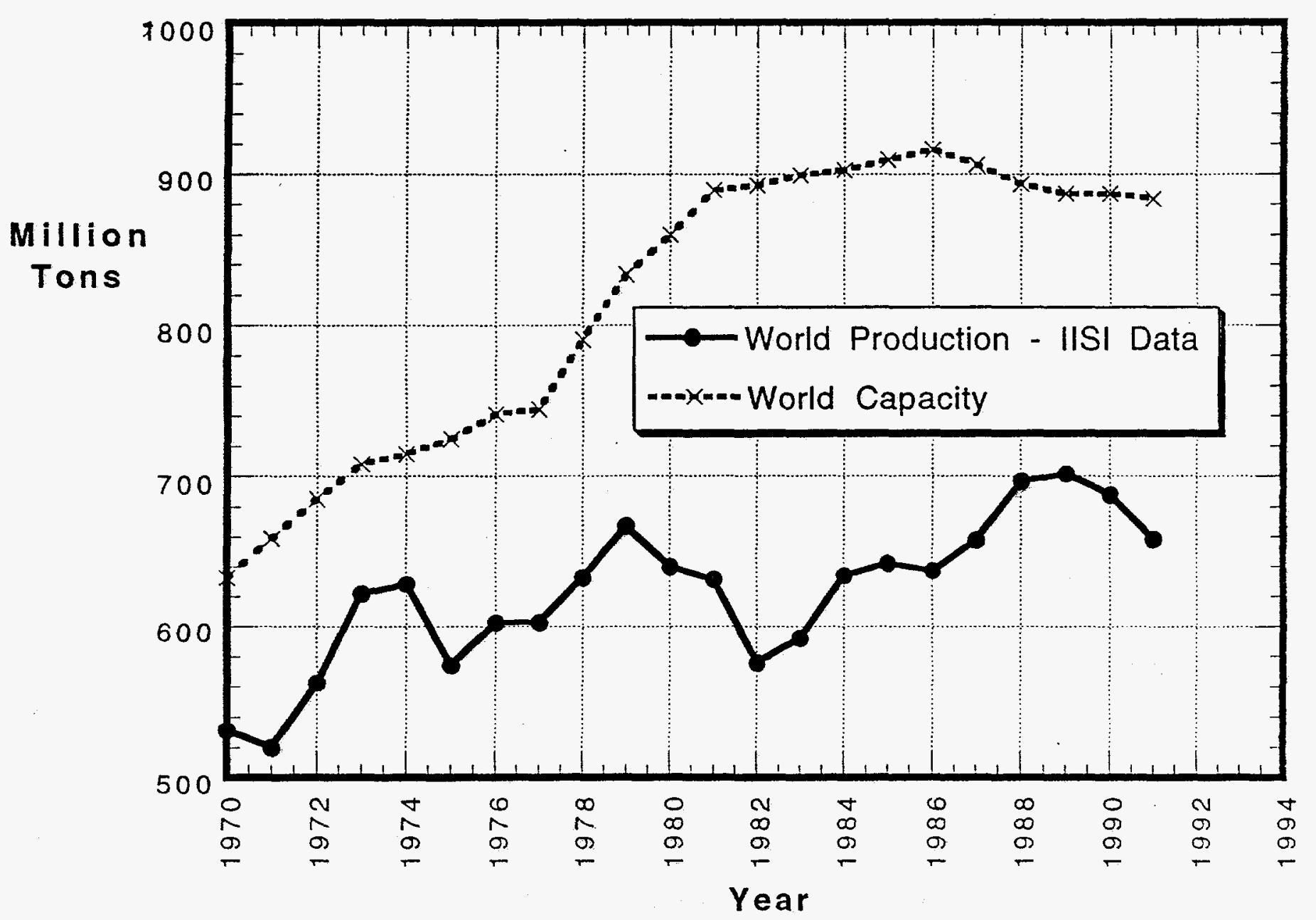

World Steel raw steel production and capacity. 


\section{PAST AND PRESENT DRIVERS COMPETITIVE FACTORS}

\section{OVERCAPACITY}

- The enormous costs to maintain these facilities worldwide are slowly being jettisoned by cooperative agreements between government groups, notably the EEC; equity considerations and the need for minimum initial size for production of classes of steel products have caused much friction.

- The steel industry in the US has undertaken to reduce its capacity by a series of mergers, rationalization of individual plant production, and closing of the least efficient facilities. The European and Japanese industry is only beginning to make these needed adjustments.

- Production of raw steel dropped by more than one third over the last twenty years; because of the advent of continuous casting and its much greater yield from raw steel to finished products, the reduction in shipments is significantly less.

e.g.

Raw steel prod. (MMt)

Shipments (MMt)

Yield
1974

145.7

109.5

$75 \%$
1986

81.6

70.3

$86 \%$
1990

99.0

85.0

$86 \%$
1992

92.9

82.2

$88.5 \%$ 


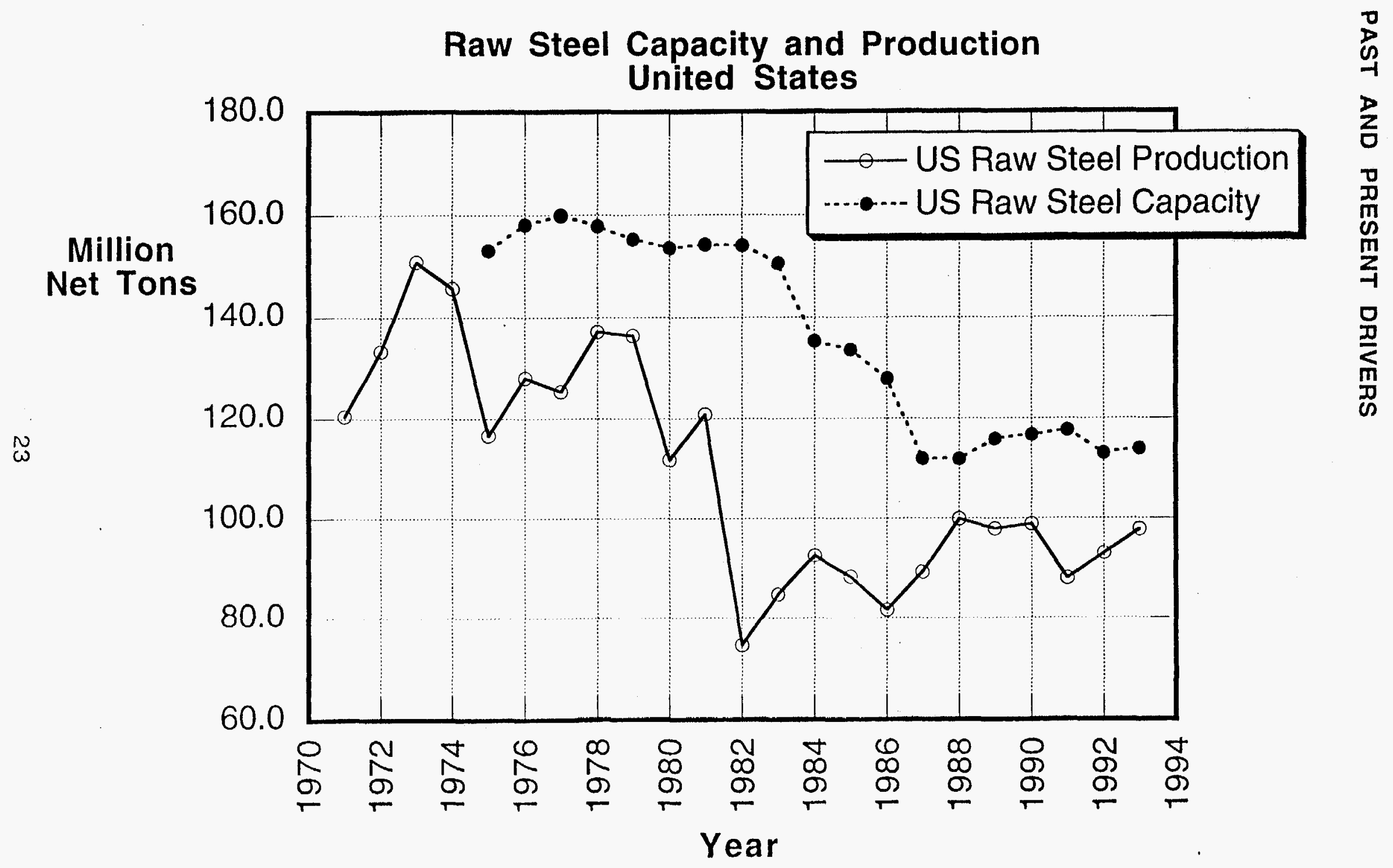




\section{PAST AND PRESENT DRIVERS}

\section{IMPORTS}

- Imports remain in the $16-20 \%$ range for a combination of reasons. For some products, the US covers only partial needs of consumers; in other cases, companies aim at diversity of supply or are tempted by attractive pricing (not always meeting fair trade criteria). Recently, large quantities of semi-finished imports have been purchased to supply the current brisk demand.

- The highest percentage of imports was $26.5 \%$ in 1984 but decreased to $18 \%$ in 1992 . The decrease was due to the better competitive position of the US industry, the VRA's and other special circumstances. Listed below are the imports (million tons) of specific products and possible reasons for the decrease.

Oil country goods Line pipe

Hot rolled sheet Cold rolled sheet Galvanized (HDG \& EG)

Wire rod
1984

2.2

1.0

3.0

3.6

2.7

1.6
1992

0.1

0.4

2.7

2.1

1.5

1.1
Possible Reasons

Energy prices were too low for active development programs in U.S

Replacement in auto transplants of Japanese steel by domestic steel

Improved US production 


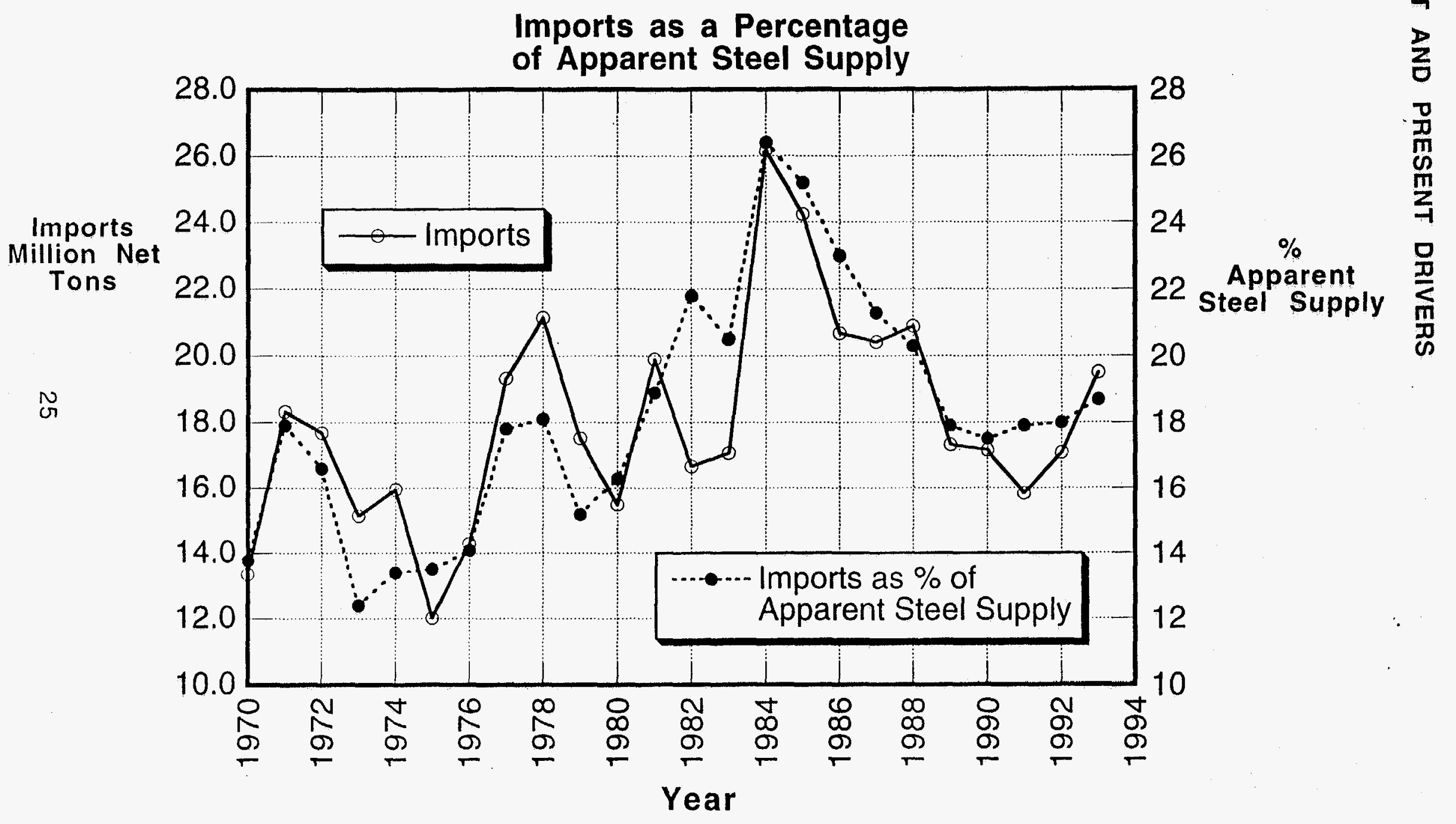




\section{PAST AND PRESENT DRIVERS SCRAP BASED PRODUCTION}

- Electric furnace melting of scrap, which at one time was largely used primarily for special steels, is now approaching $40 \%$ of raw steel production and is almost $100 \%$ continuously cast.

- Electric furnace production has lower costs because of lower capital requirements, low scrap prices and, in some cases, more effective use of labor. The development of electric furnace production has changed the industry significantly.

- Several integrated plants closed or reduced production.

- The remaining integrated mills have reacted by concentrating on higher quality products and a program of rapidly increasing quality and value.

- The market for iron ore dropped precipitously and several producing facilities were closed.

- The demand for coke decreased due to lower pig iron production along with more efficient use of coke in ironmaking. 


\section{PAST AND PRESENT DRIVERS}

\section{COMPETITIVE MATERIALS}

\section{Automotive}

- Steel remains the mainstay of the auto industry; even though the down-sizing of individual cars has reduced the weight of iron and steel per unit, the fraction of total weight has dipped only slightly. Aluminum, and to a much lesser extent magnesium, have made some advances, often as castings. Plastics have also increased usage slightly but the rate of increase is virtually zero at this time. The competition between materials hinges on relative competitiveness in several properties simultaneously, and on advances in design; steel has held up well in its delivery of increasingly useful properties over time.

\section{Construction}

- Construction competition largely comes about from wood and concrete. In housing, wood was frequently dominant until recent years when decreasing availability of good quality timber, coupled with rapidly escalating prices, has left an opening for steelframed homes. Reinforced concrete is still a strong competitor in buildings, bridges and roads, but the decentralized nature of the industry makes the recent research on cement, which could lead to lower maintenance costs, difficult to implement, so its market share remains at best static.

\section{Appliance}

- The appliance business has relied on enameled sheet steel for the last several decades. Plastics have made some inroads for items with limited structural demands but the performance has often been questionable (brittleness) and usage is apparently not increasing.

\section{Containers}

- A large market for carbonated beverage containers was lost some 20 years ago to aluminum. Only about $1 \%$ of the 100 billion cans per year are now steel and unless 


\section{PAST AND PRESENT DRIVERS COMPETITIVE MATERIALS}

some dramatic cost shifts occur, this looks likely to remain the case. Steel recycling has almost caught up with aluminum, but does not yet offer enough savings to cause a switch.

\section{Oil and Gas}

- The oil and gas business remains steel-intensive in exploration, drilling and transportation. The N. American market however has seen the number of operating units drop by almost $80 \%$ since $1980(\sim 4000$ to 800$)$ and cuts in exploration budgets have reduced the demand for pipe and tubing dramatically (from 9MMt in 1980 to -4MMt in 1992). The price of energy, especially natural gas, has been low through the eighties, but shows signs of increasing currently. 


\section{PAST AND PRESENT DRIVERS \\ COMPETITIVE FACTORS}

\section{ECONOMIC PERFORMANCE}

Integrated steel producers in the United States have sustained enormous losses, and their ability to maintain a satisfactory rate of investment in new equipment is threatened as a result.

Production, Revenues, and Profits for AISI Reporting Companies, 1982-1992

\begin{tabular}{|c|c|c|c|}
\hline Year & $\begin{array}{r}\text { Production } \\
\text { (millions of tons) }\end{array}$ & $\begin{array}{c}\text { Revenue } \\
\text { millions }\end{array}$ & $\begin{array}{c}\text { Net Income } \\
\text { millions }\end{array}$ \\
\hline 1982 & 61.23 & 28730.60 & -3383.80 \\
\hline & 67.69 & 24977.60 & -1859.90 \\
\hline 1984 & 76.80 & 30333.30 & -30.50 \\
\hline & 71.49 & 28434.40 & -1834.10 \\
\hline 1986 & 62.84 & 25036.00 & -4149.80 \\
\hline & 68.65 & 27086.90 & 1077.10 \\
\hline 1988 & 74.84 & 32670.90 & -567.40 \\
\hline & 70.52 & 31793.50 & 1596.80 \\
\hline 1990 & 70.22 & 30938.00 & 54.40 \\
\hline & 59.77 & 27073.40 & -2041.70 \\
\hline 1992 & 61.35 & 26900.10 & -3838.00 \\
\hline
\end{tabular}

Intense international and domestic competition in steel markets has had a devastating effect on the profitability of integrated firms in the United States. From 1982 to 1992, net income (profits) were positive in only three years for these producers. Losses were consistent and large in the early and mid-1980s as the restructuring took place. The return to profitability of these firms was short-lived, however. As their output plunged in the face of recession and depressed prices in the early 1990s, losses soared. 


\section{PAST AND PRESENT DRIVERS ECONOMIC PERFORMANCE}

The very poor profit picture of U.S. integrated steel firms is a relatively new phenomenon. Moreover, non-integrated steel producers in U.S. are enjoying healthy rates of return.

Rate of Return on Assets for Steel Firms in the United States and Japan

\begin{tabular}{|l|l|l|l|l|}
\hline & $\begin{array}{l}\text { U.S. } \\
\text { Integrated }\end{array}$ & $\begin{array}{l}\text { U.S. Non- } \\
\text { Integrated }\end{array}$ & $\begin{array}{l}\text { Japan } \\
\text { Integrated }\end{array}$ & $\begin{array}{l}\text { Japan Non- } \\
\text { Integrated }\end{array}$ \\
\hline $1975-1981$ & 4.62 & 8.13 & 4.02 & 3.85 \\
\hline $1981-1988$ & -5.06 & 5.22 & 3.02 & 4.49 \\
\hline
\end{tabular}

Source: W. B. Baber, Y, ljiri, and S-H Kang, Financial Analysis of the U.S., Japanese, and Korean Steel Industries. Working Paper \#024, Global Study of the Steel Industry. Page III-6.

In an extensive analysis of industry profitability in the U.S. and Japan, Baber, ljiri, and Kang found that the return on assets (ROA) of U.S. integrated firms over the period 1975-1981 (4.62 percent) was somewhat better than that of comparable Japanese firms (4.02 percent). From 1981-1988, however, the ROA for U.S. integrated producers was negative and substantial (-5.06 percent), while Japanese integrated firms continued to enjoy positive returns (3.02 percent).

In contrast, the ROA for non-integrated producers in the United States had been consistently very good. During the period of restructuring for U.S. integrated producers, non-integrated firms were making inroads in geographic areas and expanding their product lines in markets that had been dominated by integrated producers. Their record of profitability over the period 1981-1988 (ROA of 5.22 percent) reflects their success in the competitive struggle for U.S. markets.

The losses sustained by integrated producers and the debt incurred to finance productivity enhancing investment, have constrained their access to capital markets until quite recently. 


\section{PAST AND PRESENT DRIVERS}

\section{INTERNATIONAL COMPETITION}

Competition from foreign steel producers is intense in the United States, and has helped to shape the current structure of the industry. Steel production is regarded as economically and politically important in many countries, so government subsidies and support are commonplace. This has had a profound effect on the nature of international steel trade and the growth of steel capacity world wide.

A surge in imports to the United States occurred in the 1980s that promoted a industry restructuring. U.S. producers sought and won protection from steel imports, and took advantage of the relief they were granted by improving efficiency and productivity.

The crisis that brought about the restructuring of the U.S. steel industry during the 1980s had a counterpart in Europe where there was significant excess capacity to produce steel. The response to this crisis in European was managed by the government of the European Community.

Europe's plan to reduce industry capacity and stabilize prices tied the authorization of State Aids (subsidies), which were large, to the restructuring plans submitted by individual companies. Capacity reductions did take place in Europe, but they were not as large as those in the United States, and the nature of the European restructuring was clearly constrained by national politics.

As compared to U.S. and European steel makers, those in Japan have only recently been forced to consider major restructuring initiatives. Several developing nations are becoming major competitors on the world market. The expansion of capacity and production in South Korea, Taiwan, India, and Brazil has been substantial in recent years, and their gains have recently been at the expense of traditional steel producing nations. 


\section{PAST AND PRESENT DRIVERS INTERNATIONAL COMPETITION}

The intense foreign competition has forced the US industry to install technologies to improve products and productivity. However, at the same time, prices were depressed due to the foreign competition reducing the available capital.

Competition from imports has been a technology driver.

Steel producers in the United States have faced stiff competition from imports for many years. As these firms came to realize the consequences of poor investment strategies, failed labor relations, and keen domestic competition, inroads by foreign producers brought them to economic crisis.

Anti-inflation policies pursued by the U.S. government in the early 1980 's caused a surge in the value of the dollar. This attracted foreign steel producers to the U.S. market, and import penetration soared. Integrated steelmakers in the United States, already weakened by competitive pressures, including competition from minimills, took bold action.

- Firms restructured their operations. This included plant closures, capacity reductions; a narrowing of product lines, organizational changes, and a drive toward improved productivity and cost competitiveness.

- Protectionist pressures increased as U.S. steelmakers fought for trade barriers in the form of tariffs and quotas. The U.S. government responded by negotiating restrictions on trade with major steel producing nations. The resultant Voluntary Export Restraints (VERs), also known as Voluntary Restraint Agreements (VRA's), limited import penetration of the U.S. market. 


\section{PAST AND PRESENT DRIVERS INTERNATIONAL COMPETITION}

\section{Voluntary Export Restraints provided an opportunity that was used by}

U.S. Steelmakers to good advantage.

This protection from imports lasted from 1982 to 1992 . Agreements were reached first with European producers and extended to a number of other nations in 1984. Any form of trade protection runs the risk of preventing or curtailing necessary industry adjustment, but this did not happen under the VER agreements. They were effective in providing a respite for the industry that was used to good advantage by steel producers to improve their efficiency and make them more competitive in world markets.

An important reason for this was that the VERs negotiated in 1984 were accompanied by a resolution in Congress that forced domestic steel producers to reinvest their cash flow. An enormous amount of capacity was closed, and many of the remaining mills had their facilities upgraded. As the data show, not only did U.S. integrated producers return their cash on hand to productive investment, but their borrowing for new investment was substantial.

In large part, the gains in labor productivity that have been noted can be traced to higher capital-labor ratios in the industry, which can be linked to the VER policy. 


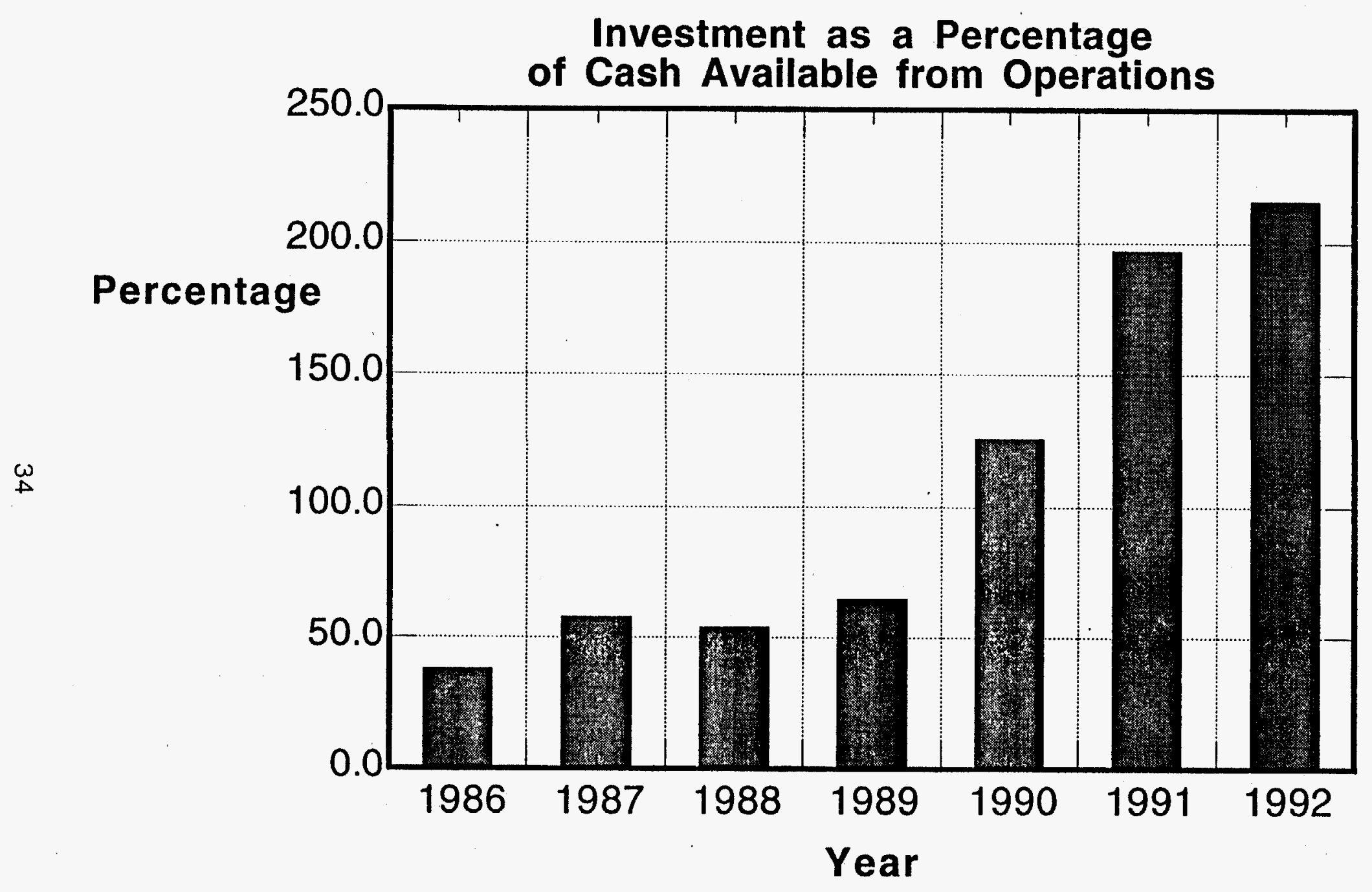

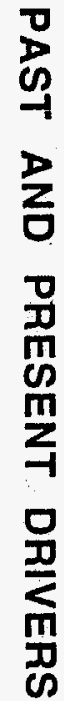




\section{PAST AND PRESENT DRIVERS INTERNATIONAL COMPETITION}

The response of the European nations to the global crisis in steel
production has been constrained by politics within the European Union.

The political basis for the European Union (EU) was laid in the Treaty of Rome (1951) that established European Coal and Steel Community (ECSC). The intention of this treaty was clearly to minimize possibilities for conflict among members by binding together the interests of all the major steel producing nations in Europe. Subsequent treaties broadened the scope of cooperation greatly and lead to enormous gains in terms of economic integration. The European response to crisis in the steel industry is governed by the treaties that established this integration and help to maintain it.

To a very large extent, European steel production and European politics are commingled. European nations are loath to accept the social consequences of plant closure; subsidies and other state aids from national governments are common, even though they are prohibited by the Treaty of Paris.

In 1980, after earlier efforts to reduce production and capacity on a voluntary basis failed, the European Commission, a governing body within the EU, established mandatory production quotas. The quotas were supported by setting a price floor for steel products, and imports to the European market were curtailed. The crisis continued to deepen, nevertheless, and by 1982 and the Commission established a plan to manage capacity reduction in the industry. In the absence of such a plan, and the strong incentives necessary to make it work, it had become obvious that many European nations stood ready to bail out failed firms in the vain hope that capacity reductions and plant closures would be forced on neighboring countries. 


\section{PAST AND PRESENT DRIVERS INTERNATIONAL COMPETITION}

The incentive to adhere to European guidelines for capacity reduction came in the form of state aid.

$$
\begin{gathered}
\text { Subsidies to the European Community } \\
\text { Steel Industry Approved by the Commission } \\
\text { January } 1980 \text { - December } 1985 \\
\text { (millions of Dollars) }
\end{gathered}
$$

\begin{tabular}{|l|c|l|c|}
\hline \multicolumn{2}{|l|}{ Types and Amount of Subsidy } & \multicolumn{2}{l|}{ Purposes and Amounts } \\
\hline Grants & $\$ 6,740$ & Investment & $\$ 11,220$ \\
\hline Loans & 21,910 & R\&D & 210 \\
\hline $\begin{array}{l}\text { Debt Conv. to } \\
\text { Capital }\end{array}$ & 1,720 & Closures & 2,110 \\
\hline & & Aid for Continued & \\
Low Interest Loans & 3,470 & Operations & 14,030 \\
\hline Other & 70 & Emergency & 9,800 \\
\hline Total & $\$ 37,370$ & Total & $\$ 37,370$ \\
\hline
\end{tabular}

Source: EC Commission, Report from the Commission to the Council on the Application of Rules on Aids to the Steel Industry, Com (86) 235 final, August 6, 1986. Converted to U.S. dollars at the average annual exchange rate listed by the International Monetary Fund.

The approval of State Aids for the purpose of capacity reductions was given initially through 1985 and subsequently extended for several more years. Subsidies would be approved by the Commission only if they were tied directly to concrete plans to close plants or reduce their capacity. Similarly, an extension of the quota system was linked to restructuring plans.

The extent of the subsidy was very large, as these official figures suggest, and may have been substantially larger in reality. Indeed, in filing for trade protection with the U.S. International Trade Commission, the U.S. steel industry argued that total subsidies to European countries through 1992 amounted to, at least, $\$ 45$ billion. 


\section{PAST AND PRESENT DRIVERS INTERNATIONAL COMPETITION}

European capacity reduction was achieved, but it was moderate as compared to the initial Commission targets, and the benefits of this restructuring were curtailed by political constraints.

The Commission had estimated that, approximately, 55 million tons of excess capacity existed in 1980 and that capacity reductions of that magnitude were necessary to stabilize the market. (Bulletin of the European Communities, \#9, Vol., 15, 1982, p. 19). To achieve this and promote efficiency it was necessary for the burden of reduction to fall disproportionately on those companies suffering the greatest losses, receiving the largest subsidies, and having the most obsolete plants. However, political realities forced the overall target to be scaled back. A new target of 30-35 million tons of capacity reduction was set.

In the end, the aid and restructuring plans agreed to by the Commission specified cuts of 26.7 million tons. (Bulletin of the European Communities, \#16, Vol., 6, 1983, p.9) The actual cuts in hot rolled capacity, the measure for capacity used by the Commission, totaled 31.1 million tons. This amounted to an 18 percent reduction of total European capacity from 1980 to 1986.

In comparison to restructuring in the United States, that in Europe was more moderate. During the period 1974-1990, employment in the U.S. steel industry fell by 68 percent and reductions in raw steelmaking capacity of 65 million tons or 35 percent occurred. This contrasts with smaller reductions in Europe, where employment fell by 57 percent and capacity fell by 19 percent over the same period.

One could argue that European plants were more modern and efficient at the outset of the crisis and that more moderate reductions should be expected in Europe for this reason. The fact remains, however, that utilization rates in Europe continue to be painfully low, and much of the benefits associated with cost savings from restructuring may be negated by this. Moreover, it is abundantly clear from published 


\section{PAST AND PRESENT DRIVERS INTERNATIONAL COMPETITION}

data that the managed approach to crisis adopted by the Europeans had the result of maintaining the status quo: Capacity reductions in Europe occurred more or less uniformly, with the exception of Germany. There was heavy pressure to spread the burden equitably across countries. Political constraints such as this inevitably reduce the gain associated with restructuring.

Today, the EU prohibits State Aids to ailing mills, but the subsidies continue, nevertheless. The result of this is that privately owned European producers, notably those in Germany and the United Kingdom, are put in an untenable competitive position.

The steel crisis has been a reality in Japan, too.

While Japanese steel production is subject to the cyclical patterns typical of this industry, it did not experience the very dramatic structural decline that occurred in the U.S. from 1979 to 1982 . Indeed, a long term trend in Japanese production is difficult to discern from these data in part because public sector construction was increased to buffer the downturns.

The world economic recession that began in 1990 has had a significant effect on the Japanese, however. U.S. steelmakers faced this recession with the benefit of having made painful but highly effective competitive adjustments, whereas reorganization in Japan had been minimal by comparison.

In addition to the pressures brought about by global excess capacity, Japanese steel products have been adversely affected by two important trends in the 1990s. The rising value of Japanese currency on world markets has significantly limited the access of Japanese producers to other markets, including the United States, and the domestic market for steel in Japan has been weakened as Japanese manufacturing, especially automobile production, has moved abroad. Japanese transplants in the 


\section{PAST AND PRESENT DRIVERS INTERNATIONAL COMPETITION}

United States and Europe have come to rely increasingly on local steel suppliers.

Coupled with a long and deep recession in Japan, these trends have placed new pressure on Japanese producers to undertake the kind of restructuring that brought new life to the U.S. steel industry. In the last two years, each of the major steel firms in Japan has implemented major cost savings programs that involve the retirement or reassignment of thousands of steelworkers.

An important aspect of global competition in the steel industry has been the recent emergence of several developing nations as major steel exporters.

\begin{tabular}{|l|l|l|l|l|l|}
\hline Year & Traditional & Emerging & Other & & $\begin{array}{l}\text { World } \\
\text { Production } \\
\text { (millions of } \\
\text { tons) }\end{array}$ \\
\hline 1985 & 70.6 & 7.0 & 22.4 & 100.0 & 793 \\
\hline 1986 & 71.3 & 7.5 & 21.2 & 100.0 & 789 \\
\hline 1987 & 71.2 & 7.9 & 20.9 & 100.0 & 811 \\
\hline 1988 & 71.4 & 8.5 & 20.1 & 100.0 & 859 \\
\hline 1989 & 71.1 & 9.0 & 19.9 & 100.0 & 865 \\
\hline 1990 & 72.4 & 8.9 & 18.7 & 100.0 & 849 \\
\hline 1991 & 72.2 & 10.4 & 17.4 & 100.0 & 811 \\
\hline 1992 & 70.9 & 11.3 & 17.8 & 100.0 & 788 \\
\hline
\end{tabular}




\section{PAST AND PRESENT DRIVERS INTERNATIONAL COMPETITION}

In recent years, South Korea, Taiwan, Brazil, and India have become significant suppliers on the world market. The share of world production accounted for by these four countries is shown above as the segment labeled "emerging" steel producers.

South Korea and Taiwan have been especially important in challenging Japan for market share in Asia, where a number of countries have demonstrated truly remarkable rates of economic growth in the last decade. More generally, the very substantial increases in production that have occurred in these countries have contributed to the downward pressure on steel prices and profitability in world markets.

The effect of this new competitive pressure was felt most directly by traditional producers in the United States, Europe, and Japan in the early 1990s, when the emerging producers increased their market share in a period of declining world output.

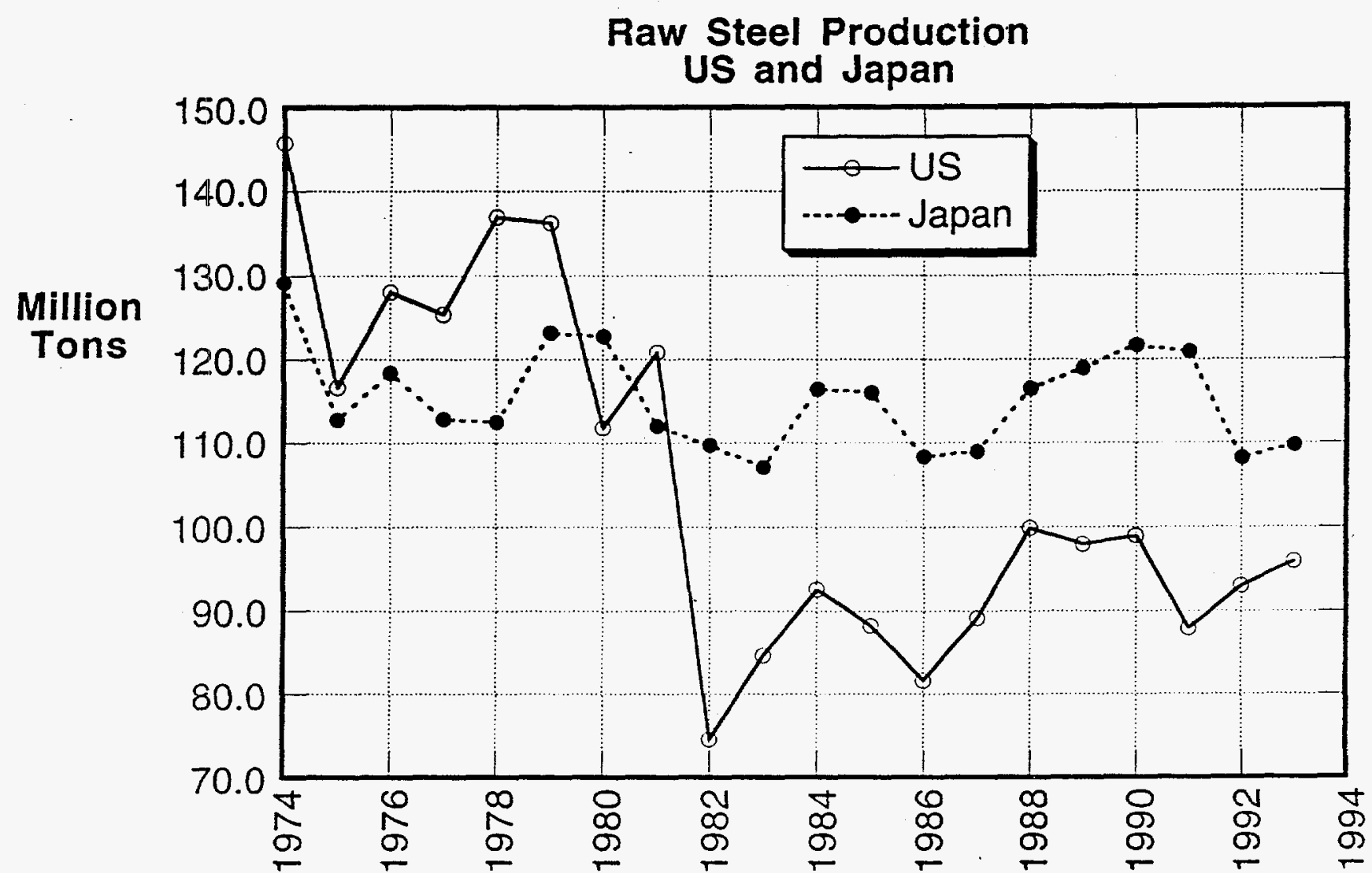

Year 


\section{PAST AND PRESENT DRIVERS}

\section{ENVIRONMENTAL CONCERNS AND REGULATIONS}

Since steel is resource intensive and generates large quantities of residuals, it has been a major target of environmental and energy regulation and been buffeted by energy shocks since 1970. The steel industry of the future will continue to be a target of environment and energy legislation, regulation, and policy. See attached figure from the International Trade Commission.

In 1987 EPA staff ranked environmental problems. Among their highest ranked problems were: criteria air pollutants, hazardous air pollutants, worker exposure to chemicals, and global warming, all primary problems of the steel industry.

A 1987-88 Roper poll indicated the public's greatest concerns were: hazardous waste sites, worker exposure to toxic substances, industrial water pollution, and industrial air pollution, all steel industry problems.

The result of these government regulations was to siphon off capital for new technologies. The percentage of capital spent on pollution controls from 1977 to 1982 was nearly $20 \%$. It decreased to about $10 \%$ or less since 1982 .

\section{GOVERNMENT REGULATION}

\section{Major legislation affecting the steel industry:}

Occupational Safety and Health Act: Set standards for safety and health in steel plants. Coke ovens became a major concern in the mid 1970s after a large increase in lung cancer risks was documented. The industry has made major expenditures to improve worker health and safety.

1970 Clean Air Act: Established National Ambient Air Quality Standards and technology based emissions standards. The industry was forced to curtail emissions of sulfur dioxide, particles and toxic releases. 


\section{PAST AND PRESENT DRIVERS \\ GOVERNMENT REGULATION}

1990 Clean Air Act: Required stringent emissions standards for toxic pollutants. A risk analysis in $\mathbf{2 0 0 0}$ will determine whether the reductions are sufficient to lower the risks of cancer to one in one-million. If not, still more stringent standards will be required. Benzene from coke ovens is a particular concern.

According to the International Trade Commission, national air pollution standards are "broadly comparable between industrialized nations."

Rio protocol: US signature in 1994 commits the USA to reduce greenhouse gases, especially ozone. Regulations or carbon taxes would hurt the steel industry. A carbon tax of $\$ 100$ per ton of carbon is estimated to raise the cost of steel by more than $\$ 100$ per ton. Various studies have estimated substantial impacts from such a large carbon tax.

1972 Clean Water Act (see also Great Lakes Water Quality Initiative): This act and subsequent amendments established water quality standards and technology based discharge standards.

Water pollution control standards are set by states and so it is difficult to compare US standards with those of other nations. Nonetheless, the standards appear to be broadly comparable and the 1982 Resource Conservation and Recovery Act (RCRA): established "cradle to grave" regulation of toxic materials to prevent the generation of new sites. RCRA covers generation, transportation, storage, use and disposal of hazardous material.

The largest difference among nations occurs for disposal of hazardous waste and treatment of toxic waste dumps, according to the International Trade Commission.

There is particular concern for dusts, sludge, and some slag. Electric Arc Furnace dust is loaded with heavy metals and so is a hazardous waste. 


\section{PAST AND PRESENT DRIVERS \\ GOVERNMENT REGULATIONS}

1980 Comprehensive Environmental Response, Compensation and Liability Act (CERCLA or Superfund): Established joint and several liability for cleanup of existing toxic waste sites.

1986 Superfund Amendments and Reauthorization Act (SARA) revises requirements and funding. Title 3 requires reporting environmental discharges of plants.

1990 Clean Air Act: Toxic air pollutants have become a focus for attention. The 1990 act requires large expenditures for control. In many places, these controls will not result in a sufficient reduction of risks and so additional, still more stringent controls will be required.

Carcinogens are a particular focus of the legislation and so have resulted in stringent standards for benzene and coal tars (coke plants) and heavy metals (blast furnace, BOF, and electric arc furnace steel making).

Concerns with tropospheric ozone are leading to concerns with emissions of volatile organic compounds (VOC) and oxides of nitrogen. The Northeastern states are setting stringent standards for emissions of NOx and VOC.

Thus the clean air Acts have required large expenditures on controlling air pollution, the Clean Water Acts have required expenditures on controlling water pollution, and CERCLA has required large expenditures on solid waste and the dumping of liquid wastes on land.

Past legislation will continue to raise environmental spending. Compliance agreements still have time to run for some plants, meaning that the plants still do not adhere to the technology based discharge standards.

Automobile Fuel Efficiency: The 1975 Energy Policy and Conservation Act required an increase in fuel efficiency for the average new car sold from $14 \mathrm{mpg}$ to 


\section{PAST AND PRESENT DRIVERS}

\section{GOVERNMENT REGULATIONS}

$27.5 \mathrm{mpg}$, i.e., Corporate Average Fleet Efficiency (CAFE). As a result, the average new car has shed about $1000 \mathrm{lbs}$ of weight. The amount of steel in a car has declined primarily due to lower total weight and somewhat to competing materials. Future legislation or consumer desires for greater fuel efficiency will lower the steel content of cars still further.

Recycling: Many local governments have recycle laws for steel cans and other materials. At present, more than $70 \%$ of the steel in cars is recycled and a large part of the steel in refrigerators and other "white goods." This percentage is likely to rise in the future, but the room for improvement is modest.

Environmental Compliance: The 1990 Clean Air Act is pushing steel companies to the edge of technology in controlling toxic pollutants, especially those from coke ovens. The controls have driven up the cost of coke and threaten to increase it still more in the future. If the risk analysis shows that levels of benzene, coal tars, and other compounds are still too high, the design of coke oven may have to change fundamentally. The higher coke prices have led to direct coal injection.

Tax Legislation: Tax Legislation has not been a significant driver in the past decade because many steel companies were not profitable and, therefore, were not affected. As the steel industry becomes more profitable it will become a technology decision driver. 


\section{PAST AND PRESENT DRIVERS}

\section{TECHNOLOGY DEVELOPMENTS}

Major technological changes occurred between 1955 and 1980 which greatly influenced our current industry structure

- Oxygen steelmaking was implemented from 1955-1991 in the USA with the majority of production installed between 1960-75. Oxygen steelmaking makes steel from hot metal in about 45 minutes compared to 4-6 hours in open hearth steelmaking. However, the process melts less scrap than the open hearth. This resulted in a scrap surplus which reduced scrap prices and allowed for the growth of electric furnace scrap melting process for steelmaking.

- Continuous casting was primarily developed in the 1960's and 1970's. Whereas there were a few continuous slab casters prior to 1975 , billet and bloom casting was implemented at a faster rate in terms of percentage of production. The combination of electric furnace steelmaking and billet casting with low capital and operating cost became the low cost method of producing reinforcing bars and simple construction materials (long products). This technology combination was economical below 0.5 million tons per year and was termed the "minimill". Integrated producers implemented continuous slab casting primarily in the 1970's and 1980's and by 1994 over $90 \%$ of steel production was by continuous casting. Continuous casting technology decreases energy consumption, improved yields, improved quality and ultimately reduces capital cost.

- High productivity EAF steelmaking made the scrap based EAF producers highly efficient. The improvement in the major operational parameters have been significant as indicated in the following table. 


\section{PAST AND PRESENT DRIVERS}

\section{TECHNOLOGICAL DEVELOPMENTS}

1970

Current

Time to produce liquid steel

180 minutes

55 minutes

Electrical Energy consumption per ton $600 \mathrm{kwh}$

$400 \mathrm{kwh}$

Electrode consumption per ton

12 pounds

4.5 pounds

Manpower per ton

3 man hours

0.4 man hours perton

These achievements were brought about by a series of technologies and management practices. The technologies included Ultra High Power (UHP) Furnaces, Ladle Furnaces, oxy-fuel burners, foamy slag practices and high use of oxygen.

- Quality improvements now allow industry to deliver material with specific properties, not just "steel".

Specifically,

- Ladle metallurgical systems have been installed which have reduced variations in chemistry and the amount of inclusions resulting in improved properties.

- Controlled cooling as the steel exits the hot rolling mill improved physical properties.

- Improved computer models of hot and cold rolling with in-line measurements have greatly decreased dimensional variations.

- Introduction of coated sheet has significantly improved corrosion properties, in particular for automotive applications. 


\section{PAST AND PRESENT DRIVERS}

\section{RECENT AND CONTINUING PRODUCTIVITY AND QUALITY IMPROVEMENTS}

The steel industry has advanced significantly in the past decade. Labor productivity has more than doubled and the US industry is the low cost producer for the US market. In addition, process and management practice improvements have made the steel quality world class.

Specifically,

- Coal injection into blast furnaces has been or is being installed and by 1996 several US plants will be leaders in this technology.

- Continuous casting has increased to about $90 \%$ of production.

- New thin slab casting is up to about 4 million tons and could be 10 to 15 million by 2000 .

- All major producers have installed vacuum degassers for improving quality and extending markets.

- Direct charging of slabs is being implemented in a number of plants.

- Many new galvanizing lines including electro-galvanizing, hot dip lines and other types of finishing lines have been installed.

- Ladle metallurgical furnaces or other steel reheating capabilities have been nearly universally installed.

- Continuous annealing of some types of sheet is being implemented.

- Statistical process control of rolling processes has been implemented along with computer models and automatic control of variables, therefore, markedly reducing variations in properties.

- Advanced controls improved all dimensions except shape.

- Flat rolled coil sizes are much larger on average. 


\section{PAST AND PRESENT DRIVERS}

\section{CAPITAL REQUIREMENTS}

The steel industry is a highly capital intensive industry. Capital costs vary greatly depending on the manufacturing system and product but range from 20 to $35 \%$ of the total cost of producing steel. Therefore, the capital costs associated with new manufacturing facilities are a major driver in selecting technologies. In particular, the capital cost for the integrated production of steel from ore and coal is extremely high and consequently much of the new capacity installed in the past 20 years has been scrap based electric furnaces. Also, the capital costs associated with conventional slab casting and subsequent rolling, along with the large capacity requirements for economic operation were drivers in the development of thin slab casting.

It is instructive to examine the capital cost for producing steel. Listed below are the approximate capital costs for new and rebuilt integrated production equipment along with those for EAF production. The figures given are only crude estimates since capital requirements are very site specific and depend on the actual equipment. Nevertheless, they do illustrate the importance of capital when selecting technologies.

Table: Capital Cost for Liquid Steel Production in an Integrated Plant

\section{$3.0 \mathrm{mt}$ annual production}

\begin{tabular}{|c|c|c|c|c|}
\hline \multirow[t]{2}{*}{ Facility } & \multirow[t]{2}{*}{$\begin{array}{l}\text { Production } \\
\text { (mt per year) }\end{array}$} & $\begin{array}{l}\text { Capital } \\
\text { (\$ million) }\end{array}$ & $\begin{array}{l}\text { Cost } \\
\text { \$/annual tonne } \\
\text { product }\end{array}$ & $\begin{array}{l}\text { Cost } \\
\text { \$/annual tonne } \\
\text { steel }\end{array}$ \\
\hline & & \multicolumn{3}{|c|}{ New Greenfield Site } \\
\hline $\begin{array}{l}\text { Coke Plant } \\
\text { Blast Furnace } \\
\text { Steelmaking }\end{array}$ & $\begin{array}{l}1.0 \\
2.5 \\
3.0\end{array}$ & $\begin{array}{l}300 \\
600 \\
550\end{array}$ & $\begin{array}{l}300 \\
240 \\
183\end{array}$ & $\begin{array}{l}100 \\
200 \\
183\end{array}$ \\
\hline \multirow[t]{2}{*}{ Totals } & 3.0 & 1450 & $-\cdots---$ & 483 \\
\hline & \multicolumn{3}{|c|}{ Rebuild and Update Existing Facility } & \\
\hline $\begin{array}{l}\text { Coke Plant } \\
\text { Blast Furnace } \\
\text { Steelmaking }\end{array}$ & $\begin{array}{l}1.0 \\
2.5 \\
3.0\end{array}$ & $\begin{array}{l}200 \\
400 \\
200\end{array}$ & $\begin{array}{r}200 \\
160 \\
67\end{array}$ & $\begin{array}{r}67 \\
133 \\
67\end{array}$ \\
\hline Totals & 3.0 & 800 & ------ & 267 \\
\hline
\end{tabular}




\section{PAST AND PRESENT DRIVERS}

\section{CAPITAL REQUIREMENTS}

Table: Capital Cost for Liquid Steel in Electric Arc Furnace Plant $1.0 \mathrm{mt}$ annual production New Greenfield Plant

Facility

Production (mt per year)
Capital

(\$ million)
Cost

(\$/annual tonne steel)

\section{Scrap Only}

$\begin{array}{lccc}\text { EAF Refining } & 1.0 & 160 & 160 \\ \text { Total } & 1.0 & 160 & 160 \\ & & \text { Scrap plus } & \\ & & 160 & \\ \text { EAF Refining } & 1.0 & 35 & 160 \\ \text { DRI/HBI } & 0.2 & 195 & 35 \\ \text { Total } & 1.0 & & 195\end{array}$

DRI/HBI assumes $20 \%$ of $1.0 \mathrm{mt}$ per facility costing $\$ 175$ million.

Production in metric tonnes $(1000 \mathrm{~kg})$ to convert to tons multiply by 0.91 .

Table: Capital Cost for Casting and Finishing to Hot Band

Facility

Conventional Slab Rolling

Thin Slab - Rolling

Conventional Slab Steckel Mill

Conventional Slab - Rolling (Rebuild)

$\begin{array}{ll}\text { Production } & \text { Capital Cost } \\ \text { (mt per year) } & \text { \$ million }\end{array}$

3.0

1.0

1.0

3.0
1000

200

250

500
Cost

\$annual tonne

333

200

250

167

Production in metric tonnes $(1000 \mathrm{~kg})$ to convert to tons multiply by 0.91 .

Thin slab rolling only has a finishing train.

Whereas these costs are only approximate, nevertheless, it is very clear that if new capacity is required, scrap based EAF has significantly lower capital cost. It should be noted scrap based EAF production cannot be used to produce all grades of steel. 


\section{PAST AND PRESENT DRIVERS}

\section{CAPITAL REQUIREMENTS}

For example, currently exposed automotive steels can only be produced by the ore based process and conventional casting. The technology must be able to produce the steel required for the market. Therefore, whereas the capital cost for EAF production is significantly lower it cannot be used exclusively.

The large difference in capital costs between integrated and EAF production has been partially responsible for the increase from less than $20 \%$ to $38 \%$ production by EAF's. The difference between conventional and thin slab casting has helped to drive the decisions in the past five years to install nearly 10 to 15 million tons of thin slab casting by 2000 . 


\section{PAST AND PRESENT DRIVERS}

\section{SCRAP PRICE AND AVAILABILITY}

Scrap is a vital raw material for steel production and represents over $60 \%$ of the iron used for steel in the US. The ore based integrated process uses about 20 to $25 \%$ scrap in the steelmaking process while electric arc furnace (EAF) production usually uses 90 to $100 \%$ scrap as its feed material. In the production of some higher quality products in the EAF 10 to $30 \%$ of the charge may be alternate iron or scrap substitutes such as some form of direct reduced iron.

The cost and availability of scrap has been a major driver in forming the structure and technologies of the current industry. The replacement of open hearths by oxygen steelmaking caused a surplus of scrap which decreased its cost and led to the expansion of electric furnace scrap melting for steel production. It takes less than $40 \%$ of the energy and $30 \%$ of the capital to produce steel from scrap in an EAF than in the traditional coke oven-blast furnace-oxygen steelmaking ore based process. The cost of producing many grades of steel is considerably less than the integrated process. These considerations have caused the percentage of steel produced in the US by electric furnaces to increase from about $15 \%$ in 1970 to $38 \%$ today.

Some major observations concerning scrap include:

- Scrap supply generally follows steel production.

- Availability of scrap used in steelmaking has grown in the past 20 years and now represents over $60 \%$ of new steel.

- The amount of home scrap generated in the plant has decreased due to the implementation of continuous casting and other yield improvements.

- The use of obsolete post consumer scrap continues to increase.

- The prompt industrial scrap from manufacturers of steel products (e.g., automotive) generally follows the economic cycle but has recently decreased due to better steel quality and improved manufacturing processes using steel.

- Until recently scrap prices have not increased significantly. They generally follow steel production increases. 


\section{PAST AND PRESENT DRIVERS}

Steel and Scrap: Supply and Demand, 1970-1993
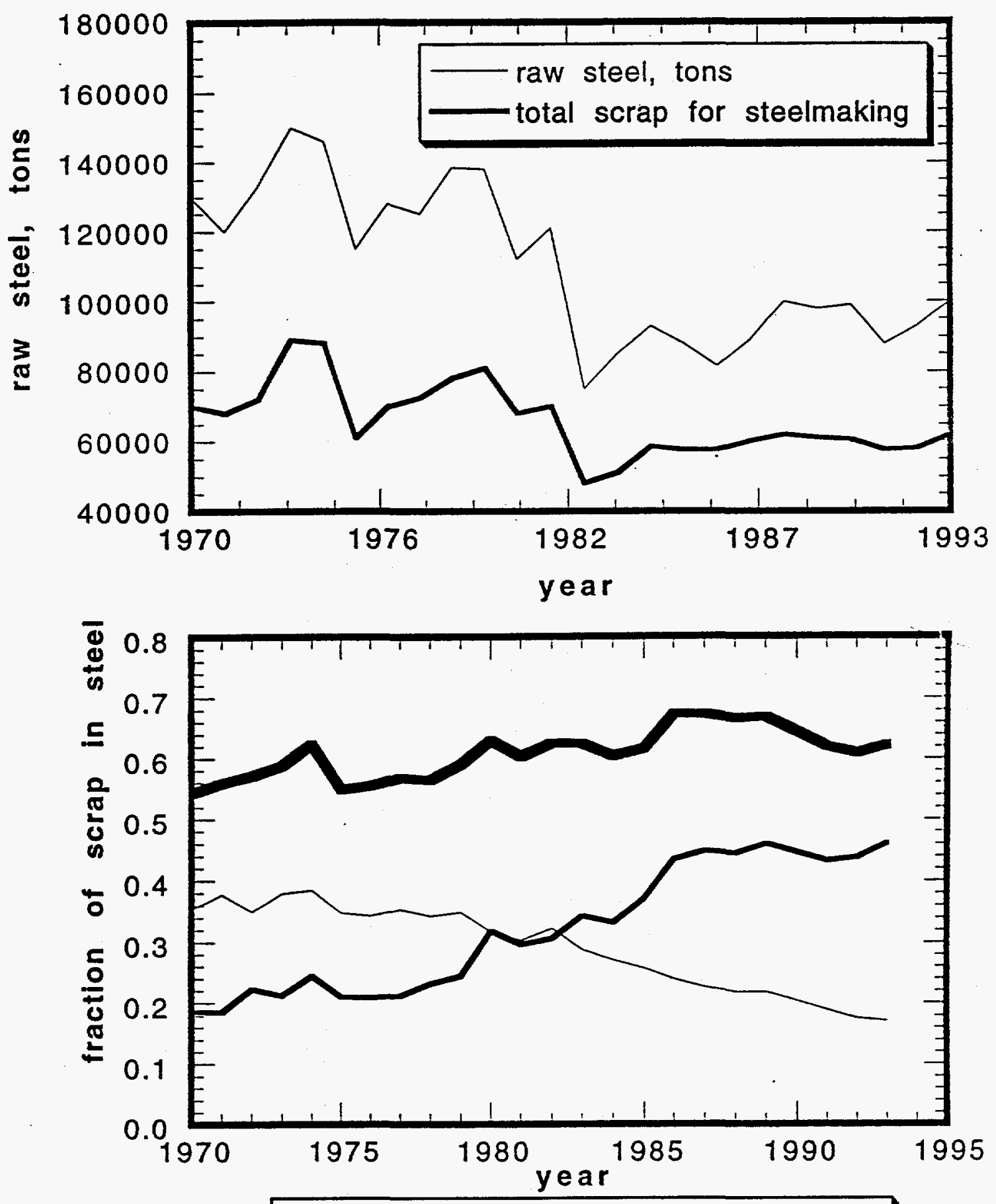

Home Scrap/Raw Steel Ton

- Total Fraction Scrap/Raw Steel Ton - Purchased Scrap/Raw Steel Ton 


\section{PAST AND PRESENT DRIVERS \\ SCRAP PRICE AND AVAILABILITY}

- The price differential between grades of scrap has remained relatively constant. The highest grade is prompt scrap from manufacturers and Number 1 Dealer Bundles.

- The price of scrap depends on the grade. Scrap price depends primarily and residual impurity elements and density.

- Scrap prices vary greatly, up to $35 \%$ in a single year.

\section{Average Price of Scrap (Dollars per ton) Chicago}

$\begin{array}{llll} & 1988 & 1991 & 1993 \\ \text { Manufacturers Bundles } & 135 & 101 & 129 \\ \text { No. 1 Bundles } & 140 & 111 & 137 \\ \text { Shredded } & 131 & 108 & 132 \\ \text { No. 1 Heavy } & 113 & 95 & 115 \\ \text { No. 2 Heavy } & 101 & 87 & 110\end{array}$

- Historically the cost of producing steel from scrap in an EAF has been significantly less than for the integrated process.

- Scrap represents approximately $60 \%$ of the cost of producing steel in an EAF.

- If scrap prices maintain the high level of late 1993 and 1994, the integrated process becomes more competitive. In particular, the variable cost which does not consider capital is lower for the integrated process when scrap prices are high. 
No. 1 Heavy Scrap Price Change, 1975-1993

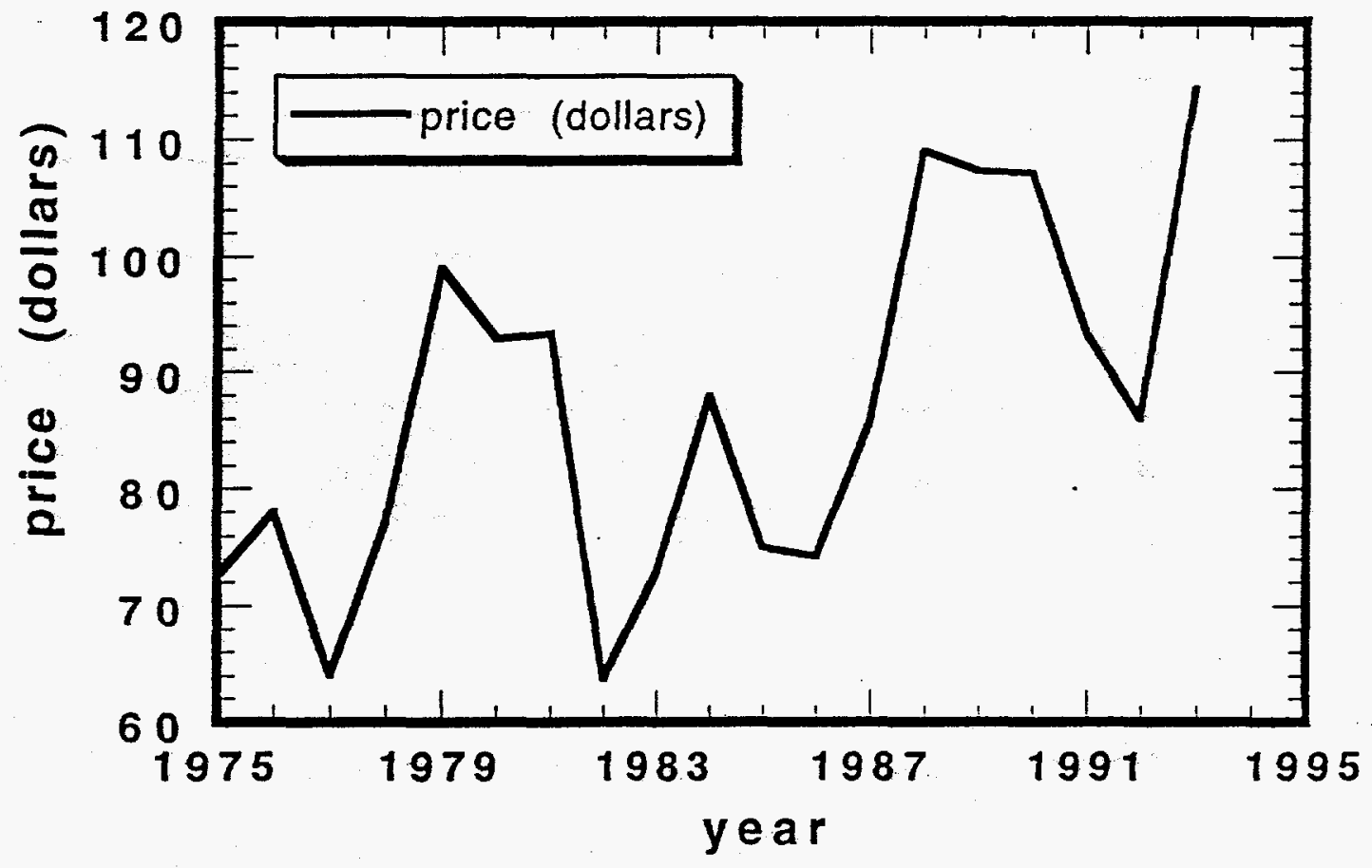


PAST AND PRESENT DRIVERS

SCRAP PRICE AND AVAILABILITY

\begin{tabular}{|c|c|c|c|c|}
\hline \multirow[b]{3}{*}{ Scrap Price } & \multicolumn{3}{|c|}{ Per Ton of Liquid Steel } & \\
\hline & \multicolumn{2}{|l|}{ EAF } & \multicolumn{2}{|c|}{ Integrated } \\
\hline & $\$ 100 /$ ton & $\$ 150 /$ ton & $\$ 100 /$ ton & $\$ 150 /$ ton \\
\hline Scrap & $\$ 110$ & $\$ 165$ & $\$ 25$ & $\$ 37$ \\
\hline Ore & -------- & --.------ & 41 & 41 \\
\hline Coke/Coal & -------- & -------- & 33 & 33 \\
\hline Electricity & 20 & 20 & 5 & 5 \\
\hline Labor & 10 & 10 & 20 & 20 \\
\hline Other & 28 & 28 & 30 & 30 \\
\hline Capital. & 25 & 25 & 65 & 65 \\
\hline Total Cost & $\$ 193$ & $\$ 248$ & $\$ 219$ & $\$ 231$ \\
\hline
\end{tabular}

NOTE: Steelmaking costs are highly variable and site specific. This simple example is presented only to indicate the major cost factors and the effect of scrap price. The costs are for liquid steel and not a finished product; finishing costs can vary greatly depending on the plant. The capital cost is for a new EAF plant and the rebuilding of an integrated plant at $8 \%$ depreciation and $8 \%$ return on investment.

- As the EAF producers expand into higher value added products they will require better grades of scrap or scrap substitutes.

- Until recently scrap substitutes have not been a major factor in steel production because their cost was high and the need low. However, recently scrap substitutes such as $\mathrm{DRI}$ and $\mathrm{HBI}$ have become more important because they are required to dilute elements such as copper, nickel, etc. to low levels. For example, to produce flat rolled steel $10 \%$ to $20 \%$ of the charge is usually a scrap substitute. 


\section{PAST AND PRESENT DRIVERS SCRAP PRICE AND AVAILABILITY}

- Scrap substitutes are usually produced using natural gas which is not available at a low enough cost for economical production in the USA. DRI and $\mathrm{HBI}$ are primarily imported from South America and Russia and DRI is only produced domestically at one plant in the USA at Georgetown SC.

The price and availability of scrap of sufficient quality has been and will continue to be a major driver for steelmaking and related technologies. 


\section{PAST AND PRESENT DRIVERS}

\section{ENERGY}

Energy is a major cost in steelmaking. The cost of energy per ton shipped accelerated after the energy crisis of the 1970's and for both the integrated and electric furnace producers was $\$ 90-100$ per shipped ton in the early 1980 's. Whereas the cost of energy per ton of steel has declined due to more efficient processing and in some cases lower unit costs it still represents about $\$ 50-60$ per ton. In examining energy consumption and cost several factors should be considered:

- Energy should be related to shipments not production. Large yield losses increase consumption per ton shipped but can decrease energy on a production basis since more steel is recycled.

- It inherently takes less than half of the energy to produce steel from scrap than from ore because it takes considerably more energy to reduce iron oxide than to simply melt iron.

- Integrated producers use fossil fuel and scrap based uses electricity. Converting fossil fuels to electricity is generally less than $50 \%$ efficient.

The steel industry has greatly decreased energy consumption and its cost.

- The industry has reduced energy consumption per ton shipped by over nearly $50 \%$ since 1975 . The decrease in energy was primarily achieved by the implementation of continuous casting and other yield improvement.

- The scrap based producers have decreased electrical energy required to produce steel by $30 \%$ in the past twenty years by implementing ladle furnaces, fast melting processes, oxyfuel burners, etc.

- Integrated producers have decreased coke rates by $30 \%$ and overall fuel rates by $20 \%$ by implementing better burden preparation, computer control, coal injection, oxygen enrichment, etc. 


\section{PAST AND PRESENT DRIVERS}

\section{HUMAN RESOURCES}

The personnel costs in producing steel products varies greatly depending on the manufacturing system (integrated or scrap based) and the product being produced. It can vary from as low as $10 \%$ for low quality reinforcing bar to as high as $25 \%$ for high quality coated products.

The industry has made tremendous strides in improving labor productivity in the past decade. Both the scrap based and the integrated producers have increased the tons per man year by nearly $250 \%$. However, labor costs are still significant since steel workers receive about $50 \%$ more income than the average for all manufacturing. Furthermore, it is one of the major controllable costs in the industry.

The industry has responded to traditionally high labor costs by implementing labor saving technologies, improved human resource practices and improved yields increasing the shipments per ton of steel produced.

- Both the integrated and scrap based producers have greatly improved labor productivity

Note: Data is from companies annual reports and is for total production and total number of workers in each company and is in metric tonnes. For US tons the man hours per ton are $10 \%$ less. [M. Lieberman and D. Johnson, Sloan Competitive Study Working Paper \#31]

- Integrated plants have reduced the man hours to produce hot rolled from over ten to about three in some plants. Nucor with EAF production and thin slab casting is less than one man hour per ton. Labor usage at Nucor is lower because it is simply melting scrap and does not have to produce iron. It also has a less labor intensive casting and finishing system with more flexibility because there is no union and better human resource management priorities, in particular its pay incentives. 


\section{PAST AND PRESENT DRIVERS}

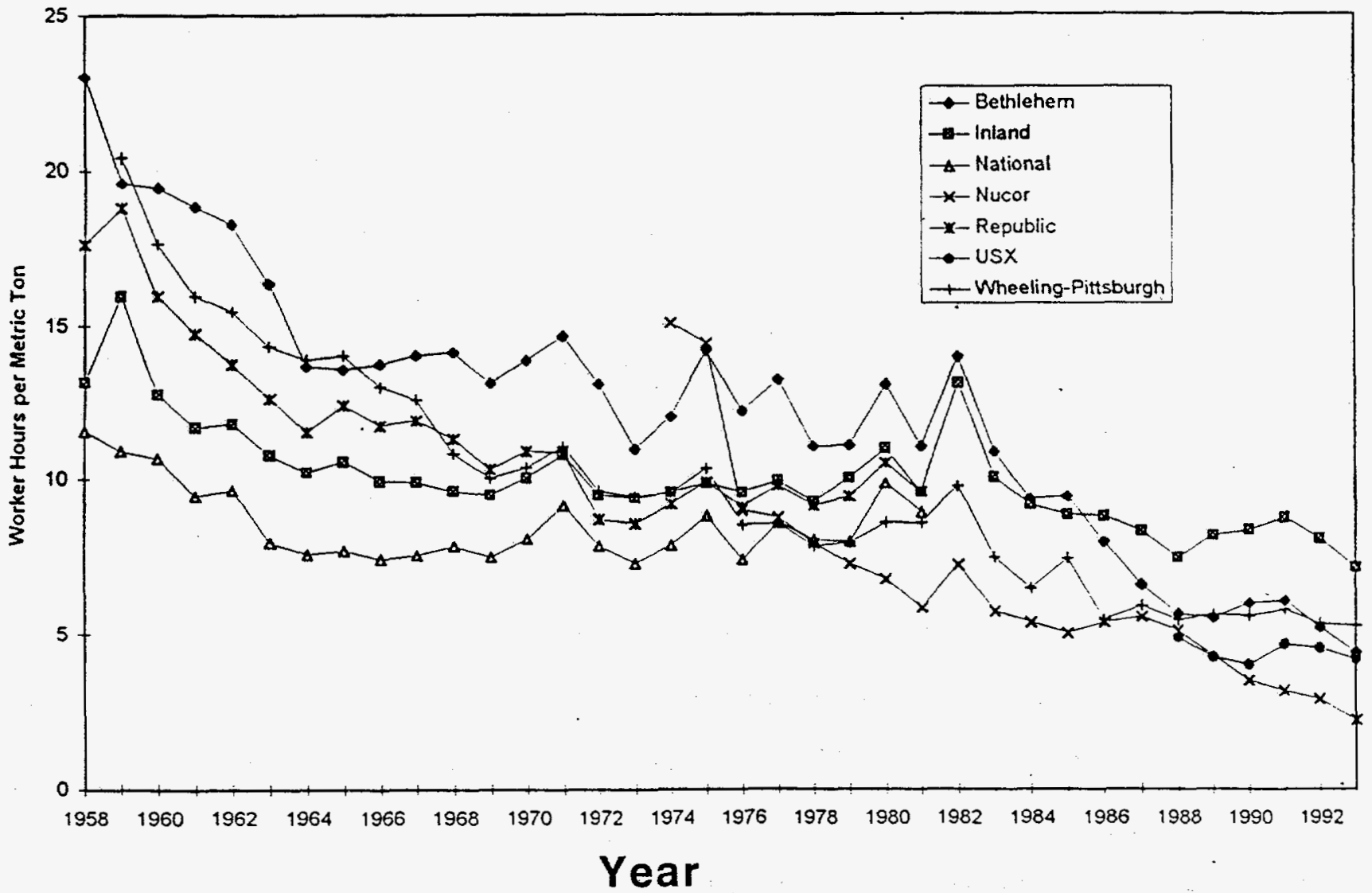




\section{PAST AND PRESENT DRIVERS}

\section{HUMAN RESOURCES}

- The steel industry's labor costs have traditionally been higher than the average of all manufacturing.

- The difference between steel and other manufacturing increased up to 1982 despite the industry's lack of performance. It decreased beginning in 1982 due to some concessions by labor.

- The premium paid by steel over all manufacturing reached a peak of $95 \%$ in 1982 and has decreased in recent years.

Premium Paid Steel Workers over all Manufacturers

1975

1982

1993
$61 \%$

$95 \%$

$35 \%$

Hourly Compensation Costs for Production Workers

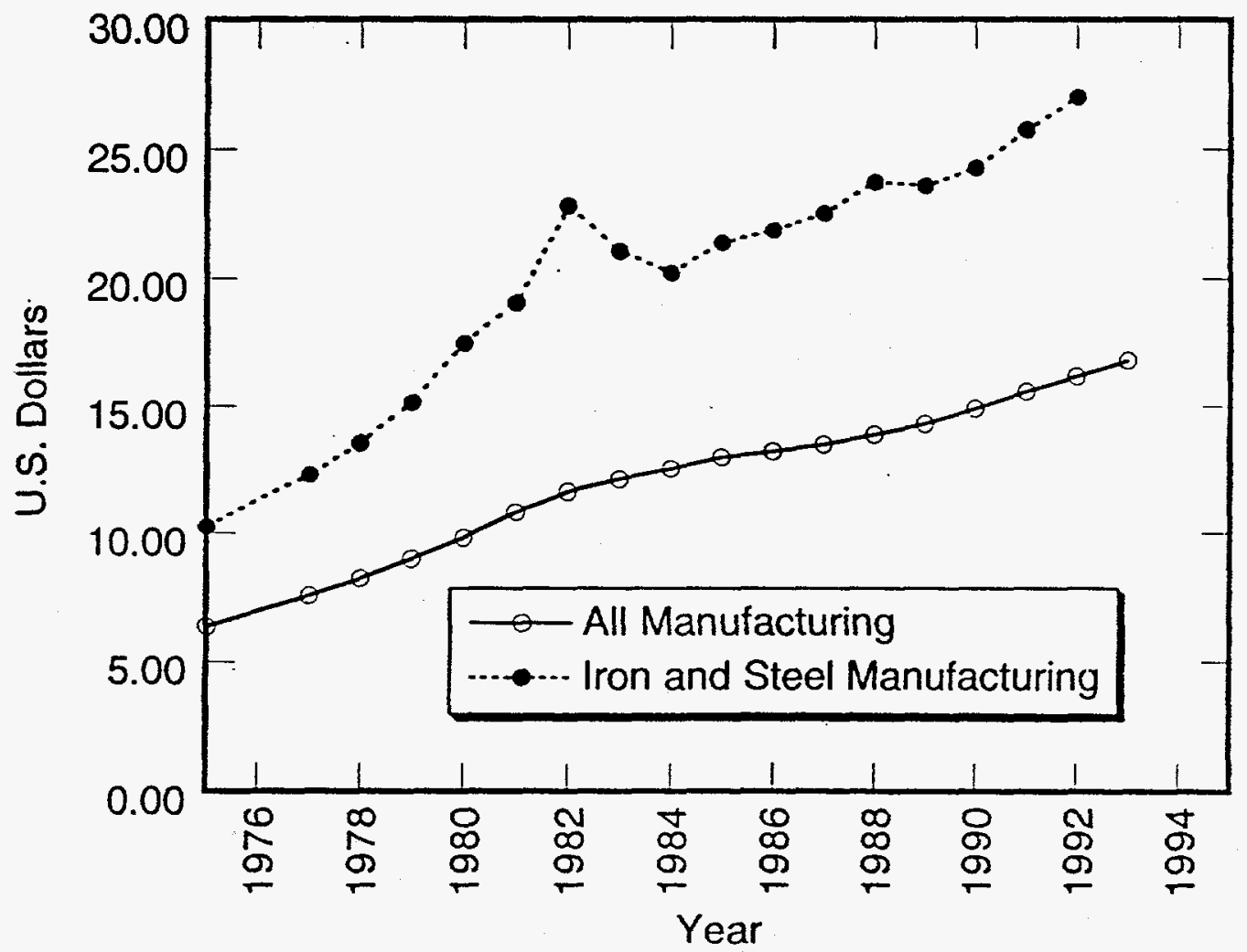




\section{PAST AND PRESENT DRIVERS}

\section{CUSTOMERS}

Customer demands and expectations have forced US producers to install technologies to meet quality requirements.

In the 1970's and early 1980's the quality of several grades of steel produced in Japan and Europe was higher than that produced in the US. Japanese automobile transplant companies demanded higher and more consistent quality, SPC, and technical audits of production. US automobile manufacturers shortly thereafter made similar demands.

- Both the integrateds producing flat rolled and the scrap based producers of special bar quality (SBQ) steels installed a variety of technologies to improve quality.

\section{Example of Customer Driven Technologies}

\section{Technology}

Bottomed Stirred BOF

Vacuum Degassers

Ladle Metallurgy Furnaces

\section{Customer Demand}

Ultra low carbon steel

Uitra low carbon steel

Clean Steel

Improved Rolling (Sensors, Models, etc.) Reduced Dimensional Variations

Coating Lines Improved Corrosion Resistance

- Companies have focused their attention to their customers. In some cases, teams of metallurgists and production workers visit customer plants. Major initiatives have been developed to make the industry more responsive to customer needs, such as the Automobile-Steel Partnership.

- The results of technological and other advances has led to much greater customer acceptance of US made steel. For example, rejection rates for steel at some automobile plants have decreased by nearly a factor of ten. US steel producers have also won some major quality awards because of their focus on customers. 


\section{CURRENT INDUSTRY}

The steel industry has gone through massive restructuring by closing inefficient plants, expanding EAF production, strategically investing in critical technologies and improved human resource and management practices. The gap between capacity and production has narrowed and there may even be a shortage of steel at peaks in the economic cycle. Imports decreased from over $26 \%$ to below $20 \%$ although there has been a recent increase due to steel shortages. Specifically:

- Integrated Plants are competitive with international plants with respect to quality and price and currently have lower cost than Germany or Japan. They are currently modestly profitable after nearly a decade of losses.

- Scrap based producers expanded into new product lines and are profitable.

- Environmentally the industry has spent billions of dollars and reduced emissions by $98 \%$ since 1970 .

- Energy consumption has decreased by $45 \%$ since 1975 primarily due to implementation of continuous casting, and increased recycling.

- Productivity of labor has increased by over $200 \%$ since 1983 and that of several processes such as the blast furnace and EAF has improved significantly.

- Customers of steel are much more satisfied with quality; rejection rates at some automobile stamping plants have decreased by a factor of ten. Steel demand is currently high, in part, due to the peak in the economic cycle; however, demand may be expected to remain reasonable due to resurgence of US manufacturing, in particular automotive and new inroads into construction markets.

- Suppliers of large production equipment such as casters and furnaces are primarily non US. Whereas technology and equipment can be purchased there is some long term concern with the lack of domestic suppliers 


\section{CURRENT INDUSTRY}

\section{CURRENT TECHNOLOGIES}

There are two methods of manufacturing steel in the US, the ore based or integrated process and the scrap based or electric furnace process. The integrated process is used primarily by the traditional steel companies "big steel", while EAF production is primarily used by the "minimill" and "market mills".

\section{ORE BASED INTEGRATED PRODUCTION}

The major "old line big steel" integrated producers have made the greatest turn around with respect to productivity and quality. The manufacturing process uses a complex series of highly capital intensive unit processes to produce high quality products, in particular, hot rolled, cold rolled and coated sheets. The industry has made tremendous improvements reducing energy by $40 \%$, labor productivity by nearly $380 \%$, reduced coke rates for ironmaking from 1125 to $800 \mathrm{lbs} / \mathrm{ton}$, and is approaching $90 \%$ continuous casting of its steel.

A simplified process flow diagram is shown below:

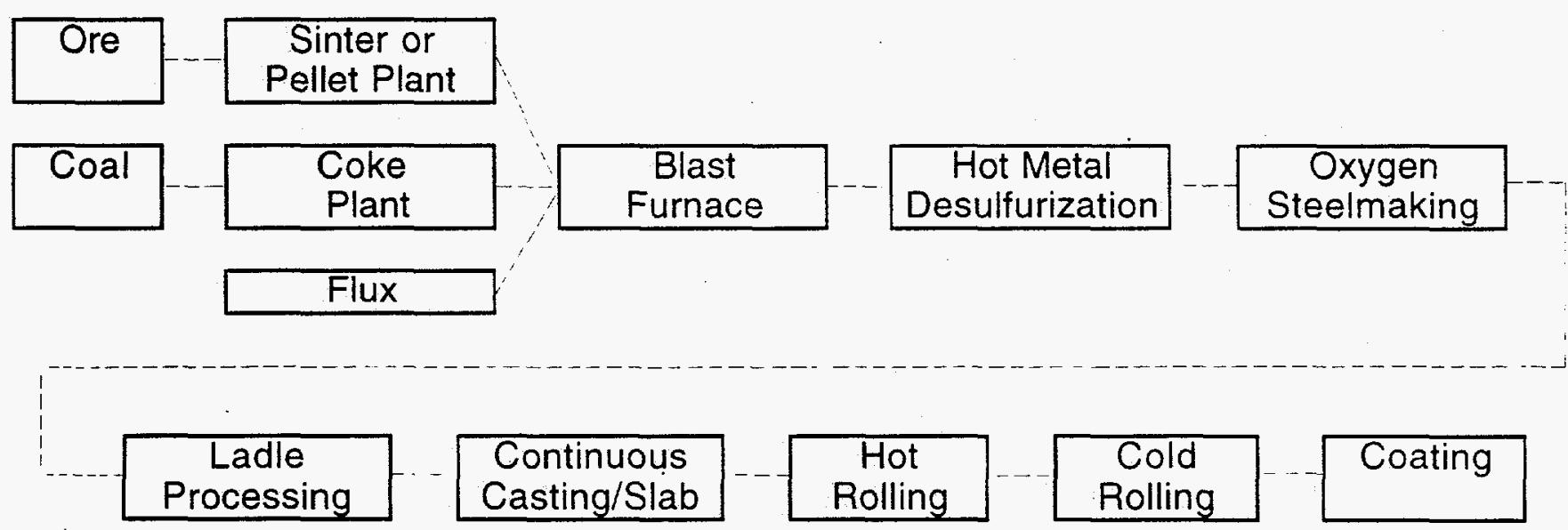

Typical Size 3-5 million tons per year

The process is capable of producing all grades of steel but, in particular, high value added and quality sheet.

The major problems associated with the process are:

- High capital cost, in particular at the front end

- Limited flexibility with regards to production

- Environmental concerns

- Processes are primarily batch rather than continuous

- Coordination between the unit operations

- Quick and reliable response to customers 


\section{CURRENT INDUSTRY}

Whereas the integrated sector still has some research and development capability this has been greatly reduced and cannot respond to all of these challenges except through cooperative programs and possibly partial government support.

\section{SCRAP BASED ELECTRIC FURNACE PRODUCTION}

The scrap based electric arc furnace (EAF) segment of the industry has made tremendous strides and prospered in the past twenty years. Their success is due to the low cost capital structure, the historic low cost and availability of scrap, innovative management and human resource practices. These plants initially focused on the lowest quality steel such as reinforcing bar but recently took over the structural market and competing effectively in hot rolled products. The scrap based industry has decreased energy consumption, greatly improved productivity, expanded into high quality products and is an international leader.

A simplified process flow diagram is given below:

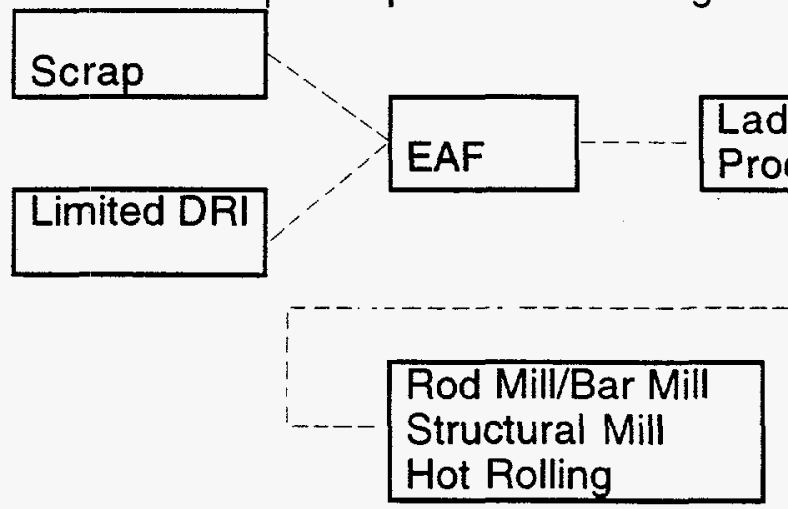

\section{Typical Size 0.5 to 2.0 million tons per year}

The process is less complex and more flexible than integrated production.

The major problems associated with the process include:

- Availability and price of high quality scrap or a scrap substitute.

- Quality of steel with respect to residuals, nitrogen, and surface quality.

- Flexible and efficient melting technologies to minimize and use various forms of energy Environmental concerns include EAF dust treatment or minimization and dioxin generation when preheating scrap.

The scrap based producers do not have large technical teams to address many of these concerns. As with the integrated producers cooperative research with partial government funding can address some of these challenges effectively. 


\section{CURRENT INDUSTRY}

\section{TECHNOLOGY}

The steel industry and its technologies have responded to the past driving forces. A few examples are given below:

\section{Industry Driver}

- International competition

- Competing materials

- Implementation of oxygen steelmaking causing scrap surplus

- High energy costs

- Environmental regulation

- High capital cost and tonnage required for conventional slab casting

- High labor costs

- Quality concerns

\section{Industry and Technology Response}

Closure of obsolete plants and strategic investment in ladle refining, continuous casting and coating lines

Development of better high strength steels and product designs

Development of the EAF "minimill" and fast melting technologies

Implementation of continuous casting, yield improvements and recycling

Implementation of pulverized coal injection (PCl), installation of facilities to improve air and water

Implementation of thin slab casting

Improved technologies and human resource management

Implementation of secondary refining, advanced computer control and sensors

It is, therefore, reasonable that the industry will need to respond to the future industry drivers discussed in the next section. 


\section{FUTURE STEEL INDUSTRY DRIVERS}

Future technological developments of the steel industry will be determined by the current and future driving forces. The future drivers will be similar to the past and current ones but their relative importance will change and the response, in some cases, must be more drastic and innovative. During the past decade, the US industry has been "playing catch up". The industry has caught up by implementing technologies primarily developed outside the US. Now, to a greater degree, the industry will have to develop its own technology to respond to its unique set of drivers. In this section, the change in emphasis and specifics for the drivers is discussed.

Competitive Factors: More pressure from competing materials, particularly in the automotive market, is expected. There could be significant expansion in the use of steel in domestic housing.

International Competition: International competition will continue in part because of international trade agreements such as NAFTA and GATT. Imports may shift from Europe and Japan to emerging nations depending on production capacity and exchange rates.

Environmental Concerns: Environmental concerns and government regulations will be even greater drivers in the future. The industry will be more proactive and less reactive as compared to the past.

Technological Changes: Several technologies are currently being implemented which will cause developments in related areas.

Capital: Lowering the capital cost of steelmaking and the associated environmental compliance will be the major driver in technology development.

Scrap and Scrap Substitutes: The price, availability and quality of charge materials will be a major factor in determining the future structure and technologies of the industry. 


\section{FUTURE INDUSTRY DRIVERS}

Energy: The past major decreases in energy consumption were primarily due to the implementation of continuous casting and a number of other small yield improvements. These sources of reduction are nearly exhausted; in the future new innovative processes are required to reduce energy cost.

Human Resources: Reducing labor costs will continue to be a technology driver. Also, education and training must play a greater role with the advanced technology to be successful.

Customers: Customer demands are increasing and will require new steelmaking processes and products.

Whereas the industry has greatly improved its competitive position in the past decade it faces enormous challenges in order to maintain or further improve its position. Due primarily to environmental concerns, the need to reduce capital, competitive materials, and the need for improved charge materials, new or improved technologies are imperative.

\section{COMPETITIVE FACTORS}

The future domestic industry will have capacity and production in reasonable balance and produce products with property combinations and work with end users on product designs to make steel more attractive. The industry will face a significant threat to its automotive market due to CAFE Standards but has a great opportunity to increase its market in domestic housing.

- Domestic steel production will be in relative balance with capacity. However there currently is 100 to 200 million tons of overcapacity world wide which will be slow to disappear; it requires world wealth to increase and in many cases there are vested interests in maintaining unneeded capacity. 


\section{FUTURE INDUSTRY DRIVERS \\ COMPETITIVE FACTORS}

-While the steel industry is inherently cyclic and the total consumption could fall from the high amounts of 1993-94 over the next few years a significant amount of the decrease could come initially from the higher recent imports, in particular, unfinished slabs.

- Historic data by product and by industry for the past 10 years indicates the displacements have been small. It is reasonable to "guess" future change will also be slow.

- The US industry will be capable of producing the vast majority of demanding steels.

- Domestic competition will be severe for the less demanding flat rolled between domestic scrap based and some integrated producers.

- A critical issue is the future value of the dollar. Strengthening seems unlikely fairly soon without markedly higher interest rates relative to the rest of the world, which in turn would have serious negative effects on the domestic economy. The degree to which redistribution of wealth takes place (.e.g., health costs, increased welfare payments) could affect the prosperity of manufacturing industries.

- The financial health of integrated companies has improved markedly e.g., recently they have been able to successfully market new shares although bond ratings have not yet improved. While not all entanglements have yet been removed (e.g., inadequate funding of some pension plans), companies are better prepared to resist the next down cycles.

- A proactive stance by combinations of steel companies (e.g., the world consortium for lightweighting a steel intensive car) bodes well for meeting challenges head-on. Most companies also on an individual basis are increasingly involved at the design stage with major customers. 


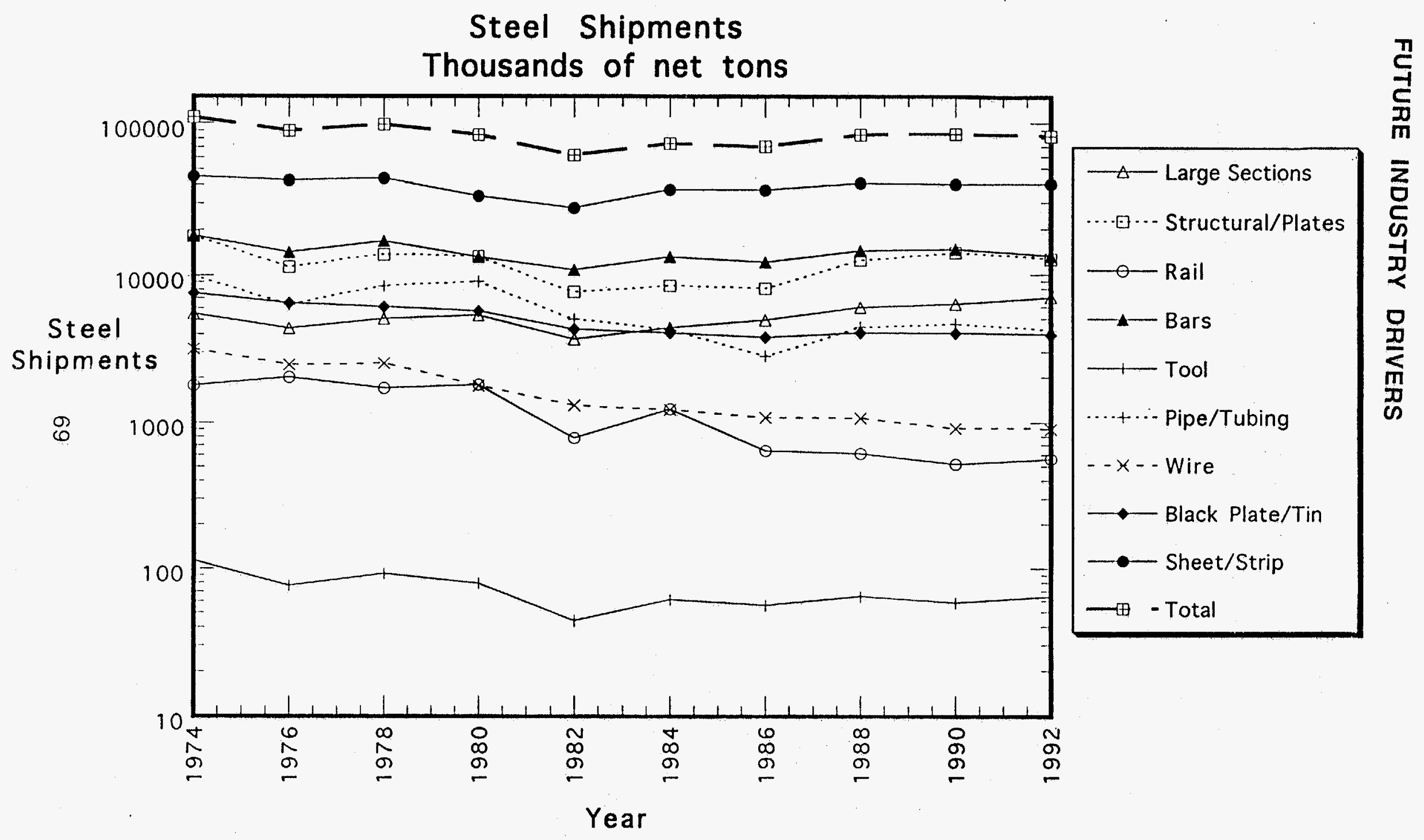




\section{FUTURE INDUSTRY DRIVERS COMPETITIVE FACTORS}

- Scrap based production currently accounts for $38 \%$ of production and most likely will grown provided that there is sufficient quality scrap and or scrap substitutes (DRI, HBI, Iron carbide, etc.). This is discussed in more detail in a separate section.

- Of the $62 \%$ produced by the integrated processes about half is not yet accessible to scrap melters using current technologies. Also since not all steel can be recovered or recycled there will always be a need for "new" iron units. Therefore an "equilibrium" between scrap and ore based production will be established close to an equal share of production.

\section{COMPETING MATERIALS}

Competing materials in various consumer groups are industry specific; their capture of market share involves considerably more than their intrinsic properties. Some of the major areas are automotive, construction, appliances, containers and oil country goods.

Automotive: This is a major and very competitive market still currently dominated by steel even though much is written of its demise in favor of aluminum and composites. The chairman of General Motors has said recently that is steel's market to lose, while also making it clear that nothing less than continuous improvement will be acceptable.

Aluminum has attractive features, such as density and corrosion resistance, but it also has drawbacks in a high volume manufacturing operation such as weldability and limits on formability. It is making headway on engine blocks as a cast material, much from recycled aluminum. With a relatively fixed world production of aluminum (approximately 20,000,000 tons) sheet for autos will have to compete with other uses of aluminum sheet (e.g., containers and aircraft) and the relative profitability becomes relevant. 


\section{FUTURE INDUSTRY DRIVERS COMPETITIVE FACTORS}

The great unknowns in the auto area for competitiveness in the medium term depend on politically controlled externalities to a large degree (e.g., CAFE, "guzzler" tax, fuel price at the pump, and recyclability). Down sizing (10 to 25\%) appears likely regardless of materials and will influence flat rolled products of all types.

One of the cooperative projects central to the current administration's wish to improve national competitiveness by having industry work with other segments of the technical world such as the National Laboratories and universities is, formally, "The Partnership for a New Generation of Vehicles", popularly known as the "super" or "clean car". It is beyond the scope of this report to examine the merits of this program. Briefly, the goal here is to develop a mid-size "green" vehicle which will have fuel economy in the range of 80 miles per gallon and meet customer's needs and preferences in safety, performance, utility and affordability. The target is a concept vehicle by 2001 and a prototype by 2005, a truly awesome program. This means a mass reduction approaching one half of today's models. Not all of this will necessarily come from reducing the density of the materials of construction. While aluminum and fiber composites meet the density criterion, they can not be substituted directly and still meet manufacturing, productivity, recycling, safety and cost issues. However, for the project to become a reality, they will certainly occupy a larger place in the automobile. The effect on steel consumption will be in the few million tons per year range.

Steel can retain more of this market by being innovative in holistic design and by accepting the need in some areas such as safety and recycling to work in a cooperative fashion with suppliers of other materials. The international steel industry in cooperation with Porsche has shown that a weight reduction of $30-40 \%$ in the automobile using steel is possible. To the degree that formability for aesthetic reasons 


\section{FUTURE INDUSTRY DRIVERS}

\section{COMPETITIVE FACTORS}

becomes less important, steel can be favored because of the reserve of potential strength in ferrous systems, even those which must be welded. In addition, an independent energy and environmental impact life cycle analysis taking into account the true recyclability of the materials should be carried out.

Construction: The home construction industry is a great opportunity. Steel housing has increased dramatically. In 1992 about 500 homes were built with steel. In 1993 the number was 15,000 and for 1994 it increased up to 75,000. By 1997, the goal is for 250,000 homes. Steel could displace large quantities of wood due to a poor of supply of high quality wood. Steel is being held back by a lack of familiarity by installers, the lack of specifications and codes, adequate standardization and thermal properties, which can be improved. The industry is developing programs with "how-to" manuals and seminars on steel housing construction.

For large structures, steel and concrete will continue to compete with no major trends apparent to cause a major shift in material choice. One possible growth area for steel is in short span bridges.

Appliances: Some inroads have been made by plastics for liners but the modulus of steel and the enameled finish possible will keep it competitive. Some switch back has already occurred. New, more efficient, horizontal-rotor washers being offered will favor steel.

Containers: Competition between steel, aluminum, and various paper and polymer macro-composites is vigorous. Beverage cans have long since gone to aluminum in the US costing steel a 2-3 million ton market at the current number of over 100 billion cans per year. Interestingly in the present turbulent scene in aluminum, several plants rolling can stock have been or are being shut down. Food cans seem 


\section{FUTURE INDUSTRY \\ COMPETITIVE FACTORS}

likely to remain steel; competition in other food packs may depend on recycling issues. Steel recycling historically has handled far more scrap than its nearest competitors some $65 \%$ or about 50 million tons per year is recycled. The "retail" scale from individual consumers is now much more active and may soon be competitive with aluminum, whereas polymer recycling is not making the progress which it needs. There is an outside chance that steel may regain a foothold in beverage cans, especially if detinning facilities continue to improve and aluminum prices continue to increase.

Oil and Gas: Drilling rig counts are down by some $80 \%$ from the high point of 1982, with a major reduction in pipelines. Since energy prices have been low, exploration budgets have been cut and coupled with offshore environmental restrictions, new finds are few. Large tankers are being scrapped; the growing demands for double hull vessels provide currently an undeterminable amount of new volume for plate. Increasingly severe requirements for offshore drilling have led to highly alloyed drill pipe; this is a market in which domestic producers no longer compete. 


\section{FUTURE INDUSTRY DRIVERS}

\section{INTERNATIONAL COMPETITION}

The profitability of U.S. steel producers will continue to be subject to the influence of politically motivated subsidies to foreign producers as well as the strategic investment policies of foreign governments. The U.S. government can be expected to continue its support to secure free and fair trade in international markets, but there is uncertainty concerning the effect that U.S. monetary policies will have on international exchange rates. As a consequence of these political forces, protectionist pressure from U.S. steel producers will continue.

- Changes in the value of the dollar on international markets are driver by policies here and abroad, but predictions concerning exchange rates are very difficult.

- Exchange rate changes can and do significantly affect the profitability of steel makers.

- U.S. government policies that cause large temporary changes in exchange rates can have long lasting effects on U.S. steel producers, in part because of the very active role that some foreign governments play in supporting steel exports.

- Enhanced trade in steel can be expected because of recent international agreements that will lower tariff barriers and limit certain types of government subsidy to steel producers.

-While the political nature of trade relations involving steel make the outcome of trade negotiations very difficult to predict, it is likely that policy changes will tend to slowly open markets and reduce trade barriers.

The profitability of all U.S. steelmakers is linked directly to import penetration, and therefore, their ability to implement and sustain investment strategies hinges on the ease with which foreign steelmakers can sell their goods in this country. If history can be used as a guide, the 


\section{FUTURE INDUSTRY DRIVERS \\ INTERNATIONAL COMPETITION}

\section{access of foreign producers to the U.S. market could well turn on government policies, here and abroad.}

Arguably, the anti-inflation policy of the Federal Reserve Bank has been the single most important determinant of import penetration in the U.S. steel market in the last decade. Inflation was wrested from the U.S. economy by restricting the money supply in the early and mid-1980s, and this forced real interest rates up to unprecedented levels. The inevitable consequence of this policy was an artificial strengthening of the dollar, and a surge of foreign imports resulted.

The general price level in the U.S. now appears to be relatively stable, but the Fed is vigilant in its battle, and has once again demonstrated its willingness to pursue tight money policies. The dollar is weak at the moment, but predictions of the direction and extent of changes in its value are fraught with uncertainty.

If one could be assured that an industry injured by tight money policies would recover without lasting effects from a temporary surge in import penetration, remedial government action (trade protection) could be difficult to justify. This is especially true if one's trading partners pursue similar policies in similar circumstances.

The reality of the steel industry is not this simple. Effects can be permanent. Foreign competitors can and do sustain strategic investment programs, gain access to new markets, and win long term advantage with government support. State ownership and subsidy are the rule rather than the exception in the world market for steel. The steel industry often plays a critical role in economic development plans as can be attested by Japan's success in the 1960s and 1970s or by the success of steel producers in Brazil, South Korea, India or Taiwan in more recent years. Even when steel firms are privately held, many, if not most, outside of the United States have recourse to government aid in times of crisis. 


\section{FUTURE INDUSTRY DRIVERS \\ INTERNATIONAL COMPETITION}

The competitive pressure on steel producers in the United States from foreign imports is likely to be unabated. However, the rules governing steel trade are subject to change under several existing or potential international agreements.

- The North American Free Trade Agreement provides for tariffs to be reduced in stages for trade among the United States, Canada and Mexico and perhaps some other countries. Similarly, the Uruguay Round of the General Agreement on Tariffs and Trade (GATT), recently approved, provides for the elimination of tariffs between the U.S. and a number of other countries over a ten year period. The countries involved in both of these agreements account for, at least, three-quarters of all U.S. steel imports and exports, as measured by the value of trade (USITC Pub. \#2759, April 1994, p. 9).

- Implementation of GATT requires new legislation in the United States and changes in U.S. trade laws. For example, the definition of "negligible imports" must be changed in the U.S. anti-dumping statutes and a five year limit would be placed on countervailing duty and anti-dumping orders, after which a review is required. (USITC Pub. \#2759, April 1994, p. 10). Also under GATT, subsidies are defined, and two specific types of subsidies are allowed: R\&D assistance to affected regions, and assistance to help meet new environmental standards, each with limits set as to the extent and nature of allowable government support. These changes are unlikely to substantially weaken existing protection for U.S. steel makers from unfair competition, but they are suggestive of the trade-offs inherent in international negotiations: The U.S. seeks new rules limiting the ability of foreign nations to provide subsidies to unprofitable firms, while other nations seek greater access to the U.S. market by trying 


\section{FUTURE INDUSTRY DRIVERS \\ INTERNATIONAL COMPETITION}

to force change in the U.S. anti-dumping laws that they perceive as being overly restrictive (unfair).

- Failure to reach agreement on the issues related to international steel trade could have jeopardized the larger GATT talks, and as a result separate negotiations were initiated with the hope of reaching a formal Multilateral Steel Agreement (MSA). If successful, this agreement would go beyond GATT in that it would place tougher restrictions on subsidies (e.g., regional assistance would not be allowed) and it would further reduce non-tariff barriers. The political sensitivity of these issues is substantial, however, and while the negotiations continue, progress is slow and their ultimate success is not assured. The passage of GATT may defuse this issue.

- At a minimum, the enhanced trade flows that are likely to result from the lowering of tariff barriers will continue to put pressure on U.S. steel producers to maintain efficient operations and reduce costs in order to remain internationally competitive. Free trade also has the effect of encouraging more specialization in product lines. Integrated producers in the United States have become more specialized in recent years, owing primarily to competition from domestic minimills, and lower tariff barriers should promote this trend. 
FUTURE INDUSTRY DRIVERS

ENVIRONMENTAL CONCERNS AND REGULATIONS

Environmental concerns and regulations with regards to discharge constraints will be one of the major future drivers for developing new technologies. Government regulations could also significantly affect steel demand. The industry will be more proactive and less reactive in the future, particularly in the area of recycling scrap and plant waste materials. These materials will be considered "man made resources" for producing new steel.

Emissions: The US signed the Rio Accords committing the nation to reduce emissions of greenhouse gases to 1990 levels by 2000 . One method, not necessarily the only or the most effective, is to increase CAFE standards. As discussed previously, this is a major threat to steel demand by the automotive industry. Energy price increases or regulations to decrease energy consumption are likely to slow the growth in GNP and steel demand. The industry itself will reduce $\mathrm{CO}_{2}$ emissions by using more recycled scrap and by improvements in yield and energy efficiency.

A full array of environmental legislation and regulations are designed to protect air, water, and to prevent toxic discharges. For example, the 1990 Clean Air Act Amendments required that companies install Maximum Available Controls on toxic emissions. Steel companies have spent tens of millions of dollars in response to this requirement, especially at coke ovens. The Act provides for a risk analysis at the end of the century to determine whether this emissions reduction has been sufficient to protect the public. If not, new controls will be required. Unless major changes are made in risk analysis, this review may indicate the need for more stringent controls. The result could be another round of controls or the closing of facilities such as aging mills or coke ovens.

The EPA has turned its attention to two areas of relevance to steel. The first is 


\section{FUTURE INDUSTRY DRIVERS}

\section{ENVIRONMENTAL CONCERNS AND REGULATIONS}

urban ozone and the second is the effect of small particles. A National Academy of Sciences Committee identified NOx emissions as the limiting factor for urban ozone in most parts of the USA. As a result, stringent NOx controls are being required in California and the Northeast. Steel mills will face NOx controls in the next few years. Several recent studies have found that small particles have effects on health at levels far below what was assumed to be safe. The result may be a tightening of the standards for emission of particles, as well as a tightening of the standards for emissions of NOx and SOx, which create aerosols. Another possible area for strict government regulation is the emission of volatile organic compounds (VOC). Thus, the steel industry seems certain to face more stringent regulations of its pollutant emissions.

\section{WASTE RECYCLE}

Solid wastes from steel plants will have to be reduced. BOF and blast furnace dusts and sludges which are typically $1-2 \%$ of production in each operation must be recycled. However, these are valuable sources of iron units. EAF dust which has been classified as a hazardous waste (KO61) and is about $0.5-2.0 \%$ of production (10$40 \mathrm{lbs}$ per ton of steel) cost up to $\$ 200$ per ton of dust for management and represent \$3-6 per ton of steel; this is a major cost and problem which will only get worse. More effective use of blast furnace BOF and EAF slags must be made. Also, processes which generate less slag will be required.

\section{STEEL PLANT REMEDIATION}

A significant long term environmental concern is the clean up of closed steelmaking facilities. It is anticipated that several cokemaking plants will be closed in the next decade. The cost of effective technologies for reclaiming these sites is unknown but probably high. 


\section{FUTURE INDUSTRY DRIVERS}

\section{TECHNOLOGICAL DRIVERS}

Technology improvements that are currently being implemented will drive other technological developments. In this section, only examples of technologies that are now available and which will encourage the development of other new developments are examined.

\section{Ironmaking}

Currently many major steel plants are installing pulverized coal injection into blast furnaces to reduce the amount of coke required. A few use natural gas for the same purpose. In order to obtain efficient operation of the furnace oxygen must be used to make the furnace operate efficiently. The amount of oxygen required is very large but the purity can be lower than used for oxygen steel making. A low cost process to produce lower purity oxygen (i.e., containing several percent nitrogen) would reduce costs.

As the productivity and coal injection increases, sensors of various types will help improve blast furnace performance. Similarly, models and expert systems which can be used to optimize the performance with high coal rates will be required.

\section{Electric Furnace Steelmaking}

Scrap preheating technologies such as Consteel and the Fuchs Shaft Furnace are being implemented. Methods of reducing dioxin formation in these are required.

Direct Current (DC) furnaces are being widely implemented. The bottom or return electrode requires new innovative approaches to reduce costs.

Ultra high power furnaces which are currently normally installed cause disturbances to the regionally electrical system called "flicker". New methods of reducing this will be required. 


\section{FUTURE INDUSTRY DRIVERS}

\section{TECHNOLOGICAL DRIVERS}

\section{THIN SLAB CASTING}

Thin slab casting is now being implemented rapidly and by 2005 about 10 million tons per year in the US alone is expected to be produced using this technology. Since more surface is produced per ton of steel much cleaner steels with respect to inclusions are required. Methods to reduce and measure inclusion content of liquid steel are required to allow these technologies to expand to higher quality steel. There is also the need for better scrap or scrap substitutes for high quality steels; this is discussed in detail elsewhere. 


\section{FUTURE DRIVERS.}

\section{CAPITAL REQUIREMENTS}

As discussed under past and present drivers the steel industry is highly capital intensive particularly for the hot or front end of integrated steel production (ore agglomeration, cokemaking, ironmaking and steelmaking). Over an entire economic cycle the return on investment cannot be justified for this complex technology. Also, the future environmental regulations and concerns will require additional large capital investments.

The capital cost for liquid steel production for a new integrated plant has been estimated to be $\$ 500$ to $\$ 1000$ per annual ton of production. This cannot be justified on expected returns. A major driver will be to develop processes which eliminate several of these unit processes (e.g., cokemaking) and have higher specific productions (tons per cubic foot per day) to reduce capital cost. Similarly by near net shape casting the overall capital cost for casting and subsequent finishing will be reduced. 


\section{FUTURE DRIVERS}

\section{SCRAP AND SCRAP SUBSTITUTES}

The price and availability of scrap and scrap substitutes will be a major factor in determining the structure of the future industry and as a critical technological driver. For example, if scrap of sufficient quality and quantity will be available at the relatively low historic price, scrap based production would grow significantly and become the dominant method of producing steel. However, scrap may not be available as needed and a finite amount of "new" steel will always be needed. Therefore, an "equilibrium" in production will be established between scrap and ore based production. Where this equilibrium will be established will depend on the availability, quality and price of scrap.

As discussed previously, not all steels can be produced from obsolete post consumer scrap. Higher quality steels require large percentages of home or prompt industrial scrap. These commodities are limited and their availability is decreasing due to the implementation of continuous casting and improved manufacturing of steel products. Scrap substitutes produced from ore can be used to supplement the scrap charge and allow the use of more obsolete scrap. Production of these materials is limited; in 199326 million and 0.5 million tons were produced in the world and USA respectively.

It is widely recognized that scrap is a major concern and it has been the subject of several major studies by industry consulting firms. In some cases these "experts" come to different conclusions as to the future scrap supply. The difference in their projections are due to the assumptions which were made.

The major assumptions include:

- Future total steel production

- Percentage of steel production which will be scrap based 


\section{FUTURE DRIVERS}

\section{SCRAP AND SCRAP SUBSTITUTES}

- Scrap recovery rates

- The availability and cost of scrap substitutes

- The ease of transport and trade of scrap

Obviously, predicting scrap availability and price as well as future production of alternate iron sources is difficult and dangerous. It is also beyond the scope of this report to carry out an independent comprehensive analysis. However, by careful examination of the conflicting previous studies and their assumptions some important conclusions with respect to the future industry and its technology needs can be made.

- Currently the US industry uses $65 \%$ recycled steel to produce new steel products. This percentage will increase modestly in the next twenty years to about $70 \%$. However, the percentage of home and prompt scrap will continue to decrease increasing the use of obsolete scrap.

- The use of scrap substitutes such as pig iron and DRI will allow the use of more obsolete scrap by simple dilution of impurities. However, these materials should not simply be viewed as substitutes but critical materials allowing for the production of quality steels in normal scrap based processes.

- The use of obsolete scrap rises and falls with steel production needs. The recycle rate typically has been $30-40 \%$ of apparent steel consumption for the $10-20$ previous years. However, in periods of high demand the recycle rate has exceeded $40 \%$ and there has been a general trend for it to increase. Due to higher demands and pressures to recycle the recovery rate in the US could exceed $50 \%$ by the year 2010 . Scrap availability projections should not be made on the basis of historical recovery rates but rather on how much scrap can be recovered economically. An acceptable detailed analysis of this type is not available in the public domain but limited analysis indicates that the theoretical recovery rate is over $50 \%$ and possibly $60 \%$. 


\section{FUTURE DRIVERS}

\section{SCRAP AND SCRAP SUBSTITUTES}

- In theory there is a tremendous scrap of reserve in the USA, estimates range up to one billion tons. However, only a small portion of this can currently be economically recovered. If demand grows, more can be reclaimed but may require new technologies.

- The US typically exports 8-10 million tons of scrap annually which could go towards domestic consumption. However, if there is a global shortage of scrap exports could grow significantly. Growth in scrap exports will also, to a large extent, depend on the availability and cost of transportation.

- The availability of low residual high quality scrap will continue to decline due to more efficient manufacturing of steel products and yield improvements in steelmaking.

- The need for low residual charge materials will be partially supplied by pig iron. Pig iron is the best of the scrap substitutes with respect to steelmaking costs. Some experts contend that pig iron can supply the charge material requirements. However, in the long term this is doubtful because of the anticipated coke shortages and in periods of high steel demand the blast furnace iron will be required for integrated steel production.

- The current processes for producing other scrap substitutes such as DRI, HBI and iron carbide are gas based and these materials will be imported into the US. For US production, coal based processes are required.

There are two basic questions with regards to scrap and its influence on the future industry.

Will there be enough obsolete scrap to supply the US industry's needs? 


\section{FUTURE DRIVERS}

\section{SCRAP AND SCRAP SUBSTITUTES}

The answer to this question obviously depends on the validity of the assumptions made. Conversely the assumptions must be consistent with the scrap available. If there is a projection of insufficient scrap it means the assumptions are incorrect. For the following set of assumptions it is reasonable to conclude there will be sufficient obsolete scrap. The scrap price will continue to fluctuate significantly with the economic cycle but the scrap will be available.

- Modest growth in US steel production (1-2\% per year).

- An increase in scrap based production from $38 \%$ to about $45-50 \%$ of total production.

- Improved scrap recovery rates to $50 \%$ of consumption for $10-20$ years previous.

- Availability of 4-6 million tons of scrap substitutes.

- No significant increase in the use of scrap in the blast furnace or BOF processes.

- The absence of large increases in scrap exports.

\section{Will there be sufficient quantities of high quality or scrap substitutes for the US industry?}

Again, the answer depends on the set of assumptions. For the anticipated growth of scrap based quality steel production, particularly in flat rolled, there will be insufficient quantities of low residual scrap. The growth of this industry segment will depend on the availability of scrap substitutes. Initially scrap substitutes will primarily be imported pig iron and $\mathrm{DRI}, \mathrm{HBI}$ and possibly carbide produced from natural gas outside the US. For future long term growth coal based solid and liquid state reduction process will be required. 


\section{FUTURE DRIVERS}

\section{ENERGY}

\section{Energy costs still represent about $10-20 \%$ of the cost of producing}

steel and more efficient and flexible processes with regards to energy will be required.

- In the future, the lines between energy and environmental concerns will continue to be blurred, in the production and use of energy, emissions are generally incurred. For example, CAFE standards can be viewed as aimed at environmental goals and could reduce steel demands.

- A significant portion of the past energy savings by the industry was by increased use of continuous casting and other yield improvements. Further improvements will be difficult and require innovative steps such as process linkage, associated controls with cogeneration, and use of waste energy.

- A major driver for technology is not only to reduce energy but to be flexible with regards to energy source. One example is the direct use of coal for ironmaking and scrap melting 
FUTURE DRIVERS

\section{HUMAN RESOURCES}

Human resource (HR) costs still range from $10 \%$ to $25 \%$ of the total cost of producing steel and are one of the few major inputs over which the producer has some control and will continue to be a major technology driver. In addition, human resource practices must adapt to the new technologies. For example, labor use and compensation must be more flexible and the need for education and training will be more critical.

The scrap based producers have helped improve their competitive position by HR practices. The integrated producers must attempt to achieve similar gains in a union environment. , especially in the area of compensation and in flexibility. Scrap based producers often have a significant portion of total compensation tied to a complex series of performance measures. This allows for a variable labor cost which is related to production and/or profits which dampens the effect of industry downturns. These programs also help to improve performance.

In addition, the scrap based producers have had more flexibility on the use of labor. With some new or rebuilt facilities the integrated producers have been able to negotiate work rules which allow greater flexibility; flexible work rules should accompany any new technical development to optimize human resources. The integrated producers must continue to strive to have fewer job classifications, multiskill training and, in general, have compensation tied to individual performance. This will be a difficult and slow task in a traditional union plant.

* Technologies that reduce labor requirements do not always insure a greater total productivity factor. A recent study [M. B. Lieberman and D. R. Johnson Sloan Working Paper \#31] indicates that the US may still slightly lag Japan in value added per employee but is significantly ahead in capital productivity and possibly in total productivity. 


\section{FUTURE DRIVERS}

\section{HUMAN RESOURCES}

\section{TRAINING AND EDUCATION}

The US steel industry is behind its international competitors in Japan and Europe with respect to training and the number of qualified engineers with specific knowledge of the industry. The future industry will be more automated, rely more heavily on advanced control systems, and will need to be more flexible, and will need to be more flexible with regards to production and products.

Specifically the US industry does not have as skilled a work force as its competitors. For example,

- Germany has a highly developed state supported apprentice program which trains individuals for three years in plants.

- Japan has over twice the number of graduate engineers per ton of steel produced than the US

- Europe and Japan both still have university programs devoted to the production and products of steel. US universities in general have abandoned education in this area, except at very few universities, in favor of so called advanced materials.

- European companies have a more structured continuing education and training programs better than the US industry.

The future industry in the US must develop processes and manufacturing systems which require fewer highly skilled workers while continuing to help provide education and training to increase the capabilities of this reduced work force. 


\section{THE FUTURE STEELMAKING INDUSTRY}

Based on the expected response to present and future drivers a vision of the future steel industry and its technologies has been developed. The vision is for the next 5 to 25 years; some of the technologies will be developed in the next decade while others will take twenty years or more. Before examining the specific technologies and their obstacles to commercialization the general characteristics of the future industry are examined.

\section{PREDICTIONS OF FUTURE INDUSTRY CHARACTERISTICS}

- Steel will be the material of choice for traditional markets and for expanding markets such as home construction by providing the customer improved properties and excellent value.

- The steel industry will be healthy and continue to play a major role in the US economy. The industry will, in general, have a better economic performance as compared to the last decade, assuming there is fair trade and reasonable government regulations.

- The US industry will be a low cost producer for its market. Assuming that the new international trade agreements lead to fair trade, taking into account dumping and government subsidies, imports will be at acceptable levels.

- Internationally, both steel production and consumption will continue to shift from its historic base (Europe, USA and Japan) towards Asia which will approach 40$50 \%$ by 2005 . In particular, South Korea continues to expand and China will become the largest producer. The degree to which this will affect the US market is still uncertain but the effect could be significant.

- Scrap based share of production will increase in the next five to ten years. Eventually an equilibrium will be established between ore and scrap based production at about equal $50 / 50$. 


\section{FUTURE INDUSTRY}

\section{GENERAL CHARACTERISTICS}

- The major drivers for the industry and its technologies will be reductions in capital requirement, adaptation to environmental regulations and changing customer requirements.

- Processes will be developed which are inherently more environmentally friendly and consistent with the goals of "Sustainable Development". These developments will be partially due to government regulations but also the industry will be more proactive, in particular with respect to recycling and waste minimization. The technologies will be designed for pollution prevention rather than relying on treatment after the process.

However, it will be difficult to respond to arbitrary regulations which do not take into account the special circumstances of the industry. In particular, the industry is highly capital intensive and cannot abandon huge investments in processes which are designed to be productive for decades. Meeting emission standards will require huge capital investments and possibly cause the closure of many facilities.

- Recycling of obsolete scrap will increase to the point where nearly all of the recoverable steel products will be used as a raw material for new steel. From 1988 to 1993 steel can and appliance recycling rates have increased from $15 \%$ to $48 \%$ and from $4 \%$ to $62 \%$ respectively; these rates should be over $75 \%$ by 2000 . To produce many products the obsolete scrap will be supplemented by scrap substitutes such as direct reduced iron.

- Recycling of plant solid wastes will increase to the point where the amount of material going to land fills will be greatly reduced. In particular, in the future, processes will be developed to treat dust of sludges from the blast furnace, BOF, and EAF and mill scale economically. 


\section{FUTURE INDUSTRY}

\section{GENERAL CHARACTERISTICS}

- Processes will be less capital intensive and will be more economical at moderate scale, one million tons or less per year. This will reduce the cost of entry into many steel markets.

- Due to environmental concerns some ore based plants will stop certain operations ("deintegration"). For example, some major plants now purchase coke, primarily imported, due to environmental costs and concerns. This trend could continue and may go all the way to slabs resulting in the closing of the entire front end of production. Most of these slabs would be imported which could be crudely viewed as importing ore and energy and exporting jobs and pollution. Traditional scrap based producers may integrate back into iron production (DRI) and forward into more complex finishing. In general, the lines between traditional ore and scrap based processes will blur.

- Technologies will be more flexible and efficient with respect to energy consumption. The processes may rely on more than one energy type. For example, ironmaking will rely on coal and gas as well as coke, and melting will be achieved using fossil fuels as well as electrical energy.

- The new technologies will be less labor intensive and rely on flexibility in the use of human resources. Cooperation between management and workers will be essential to derive the maximum benefits from new technologies.

- Technologies and products will be developed to service the market needs. This in part will be accomplished by working with the customer to understand their needs and for the customer to understand what can be delivered by the steelmaking technologies.

- Education and training will play a greater role in the future industry due to more sophisticated technologies and flexibility of labor. 


\section{FUTURE INDUSTRY}

\section{GENERAL CHARACTERISTICS}

No single manufacturing system will be best for the production of steel. The plant's specific system will depend on its market, the availability of raw materials, and availability of capital. Several large plants of four million tons or more annually will continue to supply major market segments. However, most plants will be market mills supplying the specific needs of its particular market and in some cases its geographic area.

The plants will range from traditional ore based integrated plants producing high quality plants producing high quality products to traditional obsolete scrap based electric furnace production for bars and simple construction shapes. In between plants based on new technologies will evolve. These plants will be based on new ironmaking processes, scrap alternatives, new melting technologies, near net shape casting, etc. Examples of processes are shown schematically in the following figure. 
FUTURE INDUSTRY

\section{Future Steelmaking Plants}

Conventional Integrated Process: 4.0 MTPY.

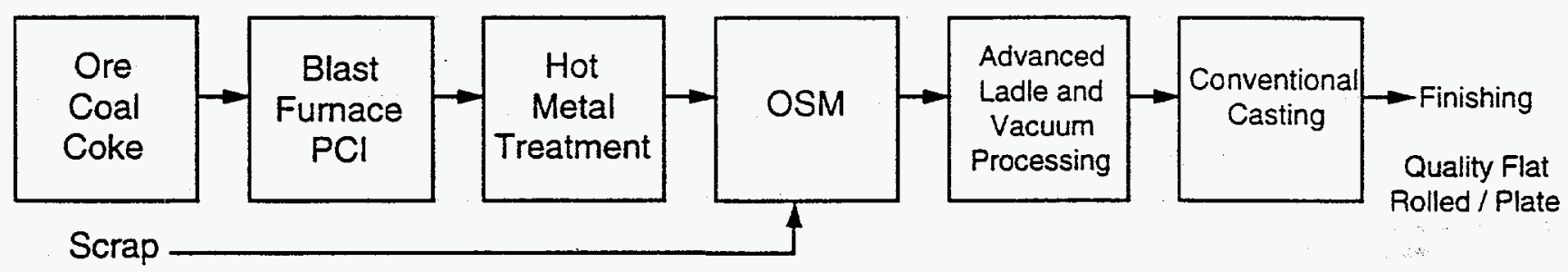

Mini Integrated Production: 1.0 - 2.0 MTPY

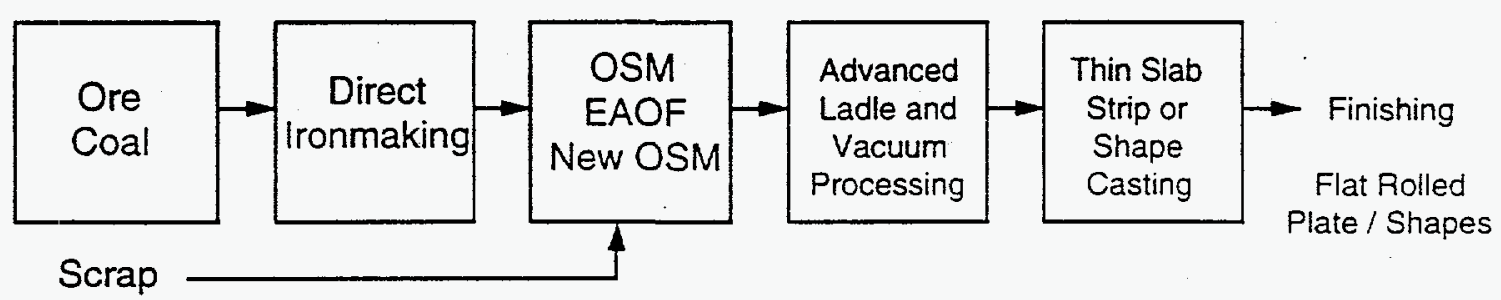

Advanced Scrap Based Production: 1.0 - 2.0 MTPY

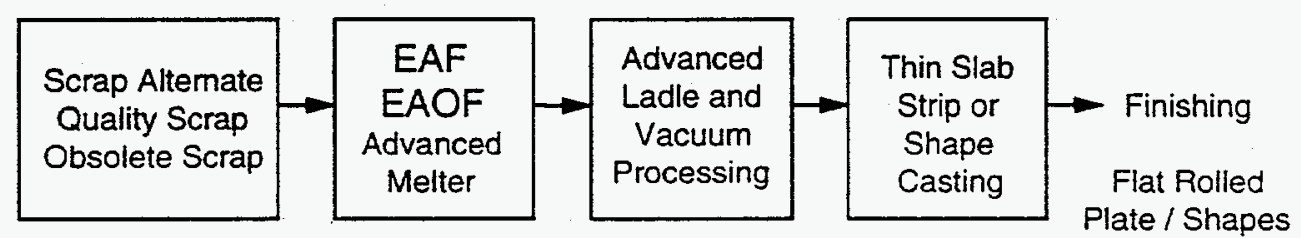

Traditional Scrap Based Production: 0.5 - 1.0 MTPY

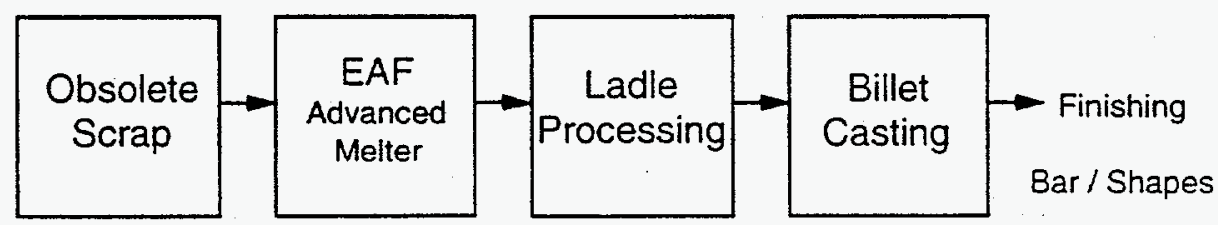

$\mathrm{PCl}$

: Pulverized Coal Injection

EAOF

: Electric Arc Oxygen Furnace

New OSM

: Continuous refining or conventional refining with scrap preheating

Advanced Melter : Fossil Fuel or hybrid melter with scrap preheating

Plants may combine technologies differently. e.g. Thin slab casting in an integrated plant 


\section{FUTURE STEELMAKING TECHNOLOGIES}

The steel industry will respond to the present and future industry drivers by adapting existing technologies or developing new technologies. It is not the purpose of this report to recommend specific technologies but rather to describe the generic characteristics these will have.

\section{COKE AND IRONMAKING}

Possibly the single most important technical challenge forcing the integrated producer is to reduce the capital cost and environmental problems associated with the present cokemaking and ironmaking processes. Whereas the iron blast furnace is a highly efficient counter current reactor and its productivity and fuel rate is being continually improved it is highly capital intensive and requires coke. Cokemaking has significant environment challenges.

There are three development paths for future ironmaking:

- Evolutionary Changes in Cokemaking and the Blast Furnace.

- Direct Ironmaking Using Coal Directly.

- New Revolutionary Processes.

\section{EVOLUTIONARY CHANGES:}

- The US producers faced with aging cokemaking facilities are and will continue to use more pulverized coal injection with oxygen. In the next five years coal rates will increase to $500 \mathrm{lbs}$. per ton of hot metal reducing coke rates to $500 \mathrm{lbs}$. on large modern furnaces.

- High coal rates will require better burden distribution and oxygen injection.

- Smaller furnaces will use natural gas or coal in moderate amounts.

- Burden preparation will improve to reduce gangue, etc. resulting in lower fuel rates and improved productivity. 


\section{FUTURE INDUSTRY}

\section{STEELMAKING TECHNOLOGIES}

- Depending on specific economic conditions, more reduced iron or scrap will be used in the burden to improve productivity.

- Top gas recirculation may be required to extend coal injection beyond $500 \mathrm{lbs}$. per ton of hot metal.

\section{DIRECT IRONMAKING:}

- Processes making liquid hot metal using coal such as AISI Direct Steelmaking, the Japanese DIOS process and Hlsmelt (Australian and Japanese) will be commercialized. The exact form of the technology may be similar to, a combination of or different from the processes currently under development.

- Processes which use coal directly and produce excess energy in the form of reducing gases such as COREX will be commercialized. To be viable the excess energy will be used for power generation, direct reduced iron production or other processes requiring large quantities of gas.

- The commercialization of COREX or the bath smelting processes will require special circumstances and will be relatively slow. Bath smelting may be initially limited to low production requirement ( $<0.5 \mathrm{mtpy})$ or special feeds such as waste oxides. These technologies will only account for less than 2 million tons per year by 2000 and less than 5 million tons by 2010 .

\section{REVOLUTIONARY IRONMAKING PROCESSES:}

- It is possible that some revolutionary processes will be developed in the next twenty five years. There are advantages of low temperature solid state reduction of ore by gas or coal followed by melting with oxygen combustion of excess carbon in the reduction product such as the new Nucor/USS (Carbide to Steel) process. The exact process or even the general concepts are not clearly defined at this time but its development is possible. 


\section{FUTURE INDUSTRY}

\section{STEELMAKING TECHNOLOGIES}

Developments in the production of oxygen gas will be required for many of the developments in ironmaking. Large quantities of oxygen lower in purity than currently required for oxygen steelmaking will be needed. Therefore, the developments in ironmaking should lead to improvements in oxygen production.

\section{OXYGEN STEELMAKING AND REFINING}

The current oxygen steelmaking processes (BOF, Q-BOP, etc.) are highly efficient processes for producing steel from hot metal. There is currently no major driver strong enough to require a near term change in this technology. However, it is not perfect; it has high capital costs, limited flexibility with respect to scrap charge, and it is actually only makes steel about one third of the time because of charging and tapping. Therefore, if a new oxygen steelmaking plant is built other alternatives will be examined which will eliminate these drawbacks.

AISI Direct Steelmaking has examined alternatives to conventional oxygen steelmaking [R. J. Fruehan, Evaluation of Steelmaking Processing, January 1994, DOE/ID/12847-5]. Two general types of processes appear to have potential benefits. Continuous refining, similar to the IRSID process, could reduce capital costs and processes which effectively utilize post combustion and scrap preheating such as the EOF (Energy Optimizing Furnace) could reduce capital cost and be more flexible with regards to scrap melting.

Therefore, potentially the future steel industry will have three types of oxygen steelmaking for converting hot metal to steel.

- Conventional processes which have been optimized including instant metal analysis, and improved refining for nitrogen and phosphorus. 


\section{FUTURE INDUSTRY}

\section{STEELMAKING TECHNOLOGIES}

- Continuous processes for hot metal treatments and oxygen steelmaking with improved productivity due to the elimination of charging and tapping time and reduced capital because the furnace does not have to rotate.

- Energy efficient processes with increased post combustion and scrap preheating to give added flexibility and reduced capital.

Refining with ladle metallurgy and hot metal pretreatments has greatly improved steel quality and reduced cost during the past ten years. Elements such as sulfur, oxygen, and hydrogen can be easily reduced to low levels and controlled. However, phosphorus removal is limited to oxygen steelmaking and, in some cases, to hot metal treatments which is not universally economical. Similarly, nitrogen removal is limited to steelmaking and may not always be satisfactory. Whereas the current ladle refining processes are, in most cases, adequate, they have high refractory and maintenance cost.

Therefore, secondary refining processes may be developed which:

- Reduce phosphorus contents

- Improve nitrogen removal in degassing

- Reduce refractory and maintenance costs.

Whereas these developments in steelmaking and refining will address some of the future industry drivers, in general, these developments are not critical as those in other areas such as ironmaking, scrap and scrap substitutes and the environment.

\section{SCRAP BASED PRODUCTION}

The major areas in which technical developments will occur for scrap based production are in charge materials, flexible efficient melting, post combustion, and environment associated problems such as EAF dust disposal and clean exhaust gases. 


\section{FUTURE INDUSTRY}

\section{STEELMAKING TECHNOLOGIES}

\section{CHARGE MATERIALS}

There have been several recent reports prepared by industry consulting groups on the availability of scrap in the future. In some respects these reports reach different conclusions based on their assumptions as discussed previously under future drivers. Nevertheless, the experts do agree on the need for low residual scrap or substitute feed materials leading to technology developments and improvements.

- The scrap industry will respond by improving scrap preparation and reducing residuals.

- Technologies for producing scrap substitutes will improve with regards to production cost and capital requirements. Most of the gas based plants will be off shore but several US companies will own or have equity positions in these plants. For domestic production a coal based process must be developed.

- Liquid hot metal could be used to supplement scrap in a few plants. The hot metal will come from one of the developing ironmaking processes such as COREX or bath smelting which will be economical on a small scale.

\section{FLEXIBLE EFFICIENT MELTING}

-Processes will develop which can melt scrap with less energy by using some form of scrap preheating. It may be a shaft type furnace, a continuous preheating charging system or an improved batch process.

- Improvements in the power supply and melting systems will be developed to reduce line disturbance ("flicker").

- Melting technologies will be developed using fossil fuel for part or all of the energy. The use of coal or gas efficiently will reduce costs and add flexibility.

- Many of the new developments in scrap melting will require oxygen leading to the development of lower cost oxygen production or compact plants for traditional EAF 


\section{FUTURE INDUSTRY}

\section{STEELMAKING TECHNOLOGIES}

plants.

\section{EAF DUST:}

Processes will be developed to minimize and effectively treat EAF dusts. The iron portion will be used for steel production.

\section{SOLIDIFICATION PROCESSES}

No single casting process will dominate the steel industry of the future. Conventional slab casting, thin slab casting and new strip casting processes will be used to produce flat products effectively. The process used will depend on market and production requirements. Billet casting for bars will be similar to today's technologies. For constructional shapes, rails, etc., specific near net shapes will be cast. Casting machines will be more flexible and be capable of casting various widths, thickness and shapes.

It is certain that new solidification processes including strip casting for carbon steel will be developed and most likely commercialized in the next five to ten years. The commercialization of thin slab casting has caused major changes in the industry; strip casting potentially will have a similar effect. However, its application will initially be limited to plants with relatively low production requirements $(500,000$ tonnes). Also, initially it will be for product widths ( $<60$ inches) not competitive with conventional or thin slab casters. For carbon steels the processes most likely will be twin roll rather than single roll for a variety of reasons including thickness requirements for further rolling, production requirements and surface quality. Single roll casting may be effective for stainless steels and special alloys. More exotic casting processes such as spray casting, electromagnetic levitation casting, etc. will not play a major role in the future industry for at least 20 years or more.

It is one thing to make these processes work; it is another to have a process 


\section{FUTURE INDUSTRY}

\section{STEELMAKING TECHNOLOGIES}

which can economically produce steel for reasonably sized markets. Several developments will be required to successfully commercialize these processes; these are discussed later.

\section{FINISHING PROCESSES AND PRODUCTS}

The current industry is currently capable of delivering from caster slabs, billets and blooms, steel of well controlled composition and substantially free of defects. There has been tremendous improvement in the quality and productivity in finishing; future gains will occur but will be relatively smaller. There will be more coupling of processes to save energy, handling cost, and time. The capital cost for several processes such as continuous annealing will decrease by improved technology.

Specifically:

- Great improvements have occurred in the last decade and much current equipment in the US is now up to the world best. Further improvements are still possible but will be small relative to those already achieved (e.g., throughput in reheat furnaces is up by $450 \%$ with energy use down by a factor of three).

- Geographical layout is still a barrier to hot charging as an energy saver. It is unlikely to change much in integrated mills.

- Products from the best hot mills can match or exceed all reasonable requirements on quality, including surface, shape and properties.

- Productivity and control are now close to the best available with current technology for the leading suppliers of the highest quality products. Developments in control remain possible to improve various features such as properties and internal quality not currently easily measured. Some alternative roll stands (work roll bending and shifting, continuously variable crown and pair-crossed rolls) can offer improvements in dimensional uniformity and consistency but may not always offer an 


\section{FUTURE INDUSTRY}

\section{STEELMAKING TECHNOLOGIES}

attractive economic return. Further work, probably by joint research, on heating controls, compact hot strip mills, Steckel mills, direct charging and rolling, plate coilers, run out table cooling on the ASM, and improvements in roll technology offers future payoffs - not necessarily all in one plant.

- Secondary suppliers can be and are profitable serving price-conscious markets.

- Downstream from the hot mill coiler, coupled processes (e.g., pickling and the cold mill, temper rolling after a continuous anneal line) are increasingly common and add to efficiency in long product runs but with a loss in flexibility in producing smaller orders.

- Continuous annealing of sheet (other than tinplate where the practice has long been standard) has not been widely used in the US. Many apparently believe that while technically attractive, it may not be economic in today's market place. Advances in box-annealing, especially by improving heat transfer have kept this process competitive.

- The situation in long products (bars, rods, etc.), beams, and plate has followed a similar course to that in sheet but perhaps because of a more fragmented market, has not moved as rapidly or on average quite so far. Important issues involve such items as billet source, control of the reheat furnace, rolling technologies, inspection and testing. A recent study shows that the US still lags foreign producers in applying the latest technology, but differences in profitability are more likely to be due to commercial considerations.

- Advances in producing high quality special purpose, and/or high strength plates, beams and sheets directly from a rolling mill with controlled cooling have been very significant but the weakness of markets for the plate products have left a glut of 


\section{FUTURE INDUSTRY}

\section{STEELMAKING TECHNOLOGIES}

under-utilized mills and several closures.

- Coated products use will expand. The use of coatings to provide corrosion protection (tin or various zinc coatings) or aesthetic appeal (paint, enamel) has grown considerably. There may be opportunities for other coatings such as alloy electroplated or exposed quality galvannealed, or alternate ways of applying current or related coatings.

- Large discontinuities in product offerings typically do not occur in the steel industry - the last example is probably the introduction of electrogalvanized sheet (and even that was a second introduction after a decade hiatus until regulatory changes). However, there are continuing improvements under way which eventually can be construed as new products when they move far enough from the base to permit uses previously inaccessible. A good example is the continuing development of increasingly low carbon content in sheet; by also adding carbide formers to reduce the carbon in solution, the mechanical properties are changed further.

Other sheets involve "dual-phase" technology and the ability to be bake hardened during painting.

- There are opportunities for further improvements in simulated service testing to improve prediction of service performance.

- Advances in cooperative design with customers, including improved forming and joining technologies, will help to stem the challenge from competitive materials.

- Many of the above points will require imaginative research consortia; perhaps with government support, and including other industries which may in part be competitive. 


\section{FUTURE INDUSTRY}

\section{STEELMAKING TECHNOLOGIES}

\section{PROCESS LINKAGE AND GLOBAL OPTIMIZATION}

The future industry will link unit operations more closely and optimize the entire steelmaking process from ironmaking through steelmaking rather just unit processes. Direct linkage such as direct rolling of slabs will reduce energy, capital and inventory cots. Other possibilities include scrap preheating, continuous desulfurization of hot metal from blast furnaces or direct ironmaking processes and more compact continuous annealing processes.

As part of the Sloan Competitiveness Study [R. J. Fruehan et al - Iron and Steelmaking, January 1994 , p. 25] the efficiency of over forty steel plants was analyzed. One of the major findings was that the individual unit processes were often reasonably efficient but the entire plant was not due to imbalances in production and quality capabilities of the various units. The future plants will be in better balance thereby increasing productivity and decreasing energy, cost and delivery times. 


\section{CHALLENGES AND OPPORTUNITIES FOR FUTURE STEELMAKING}

There are numerous challenges to the development of the proposed vision of the future steelmaking industry. These can be roughly divided into economic and technical. This report primarily deals with the technological challenges and opportunities, however, the economic requirements must be satisfied before the development or commercialization of any new technologies can be achieved. Also, the industry's research capabilities and international developments which will affect the development of the vision should be briefly examined.

\section{ECONOMIC PREREQUISITES TO TECHNOLOGY DEVELOPMENT AND COMMERCIALIZATION}

Before research, development and commercialization can occur certain economic and business fundamentals must be fulfilled. It is beyond the scope of this report to discuss these in detail but they must be considered.

- The industry must have sufficient profitability to carry out research and development activities.

- The technology being developed must satisfy the industry drivers and have a projected return on the capital investment including developmental cost to warrant its development.

- The technology must fit the individual companies long term business strategy, in particular, market strategy and how it will fit with the other current and future technologies.

The commercialization of a new technology has tremendous barriers due to high capital requirements and the inability of the industry to take unacceptable risks.

- New technologies will be commercialized under special circumstances. For example, "Direct Ironmaking" may be commercialized initially as a waste recycle technology or near net shape casting in new small plants where the rate of capital 
FUTURE INDUSTRY

\section{CHALLENGES AND OPPORTUNITIES}

return will be attractive.

- Due to the risk, the capital requirements, and the need for technical expertise the commercialization of new technologies may be done on a collaborative rather than individual company basis.

\section{CURRENT NATIONAL AND INTERNATIONAL TECHNOLOGICAL CAPABILITIES AND DEVELOPMENTS}

Before examining the technical challenges and research and development opportunities for achieving the vision of the future steel industry current developments should be examined. In this section, the US industry's research capabilities are briefly discussed and contrasted to its international competitors. Also, major current technical developments in the US and internationally which will influence the current vision are reviewed.

Research and Development Capabilities: A part of the Sloan Steel Industry Competitiveness Study examined the research capabilities of most of the US companies and selected international companies [R.J. Fruehan, Sloan Competitiveness Study, Report in preparation]. Some of the relevant highlights of the study are given below.

- The number of researchers in US companies has decreased by over $60 \%$ in the past 15 years. However, by being more focused and involved with plants and customers directly, and by collaboration, the research efforts may be more effective in some areas than in the past with much larger research staffs. 


\section{FUTURE INDUSTRY}

\section{CHALLENGES AND OPPORTUNITIES}

- The major integrated companies (e.g., USS, LTV, Inland, Bethlehem, National, Armco) maintain active research groups with fewer people. Many former research functions now rest with plant technology groups.

- With some notable exceptions such as Timken, Lukens, and others, the scrap based producers do not have a separate research organization but development is done by plant and engineering personnel.

- As compared to the selected non US producers (Nippon Steel, Usinor Sacilor and BHP) the US spends half as much a percentage on sales and research. Nippon Steel and Usinor Sacilor are two of the largest companies in the world and BHP is currently active in expansion. The US ore based producers have about ten professional researchers per million tons of production compared to thirty-five for the international groups. The scrap based producers on average have a much smaller number.

- The distribution of research is similar for the two groups, with the exception of fundamental research.

- Collaborative research is more formally structured and at a much greater level in Europe and Japan than in the US.

- Long term research (three years or more before commercialization) for US companies is limited and largely involves collaborative programs.

- Fundamental research is no longer carried out by US companies, with a few exceptions in product related areas. The major centers for basic research are at Carnegie Mellon University (CISR) for research on ironmaking through the strip casting and at Colorado School of Mines (SRC) for finishing. 


\section{FUTURE INDUSTRY}

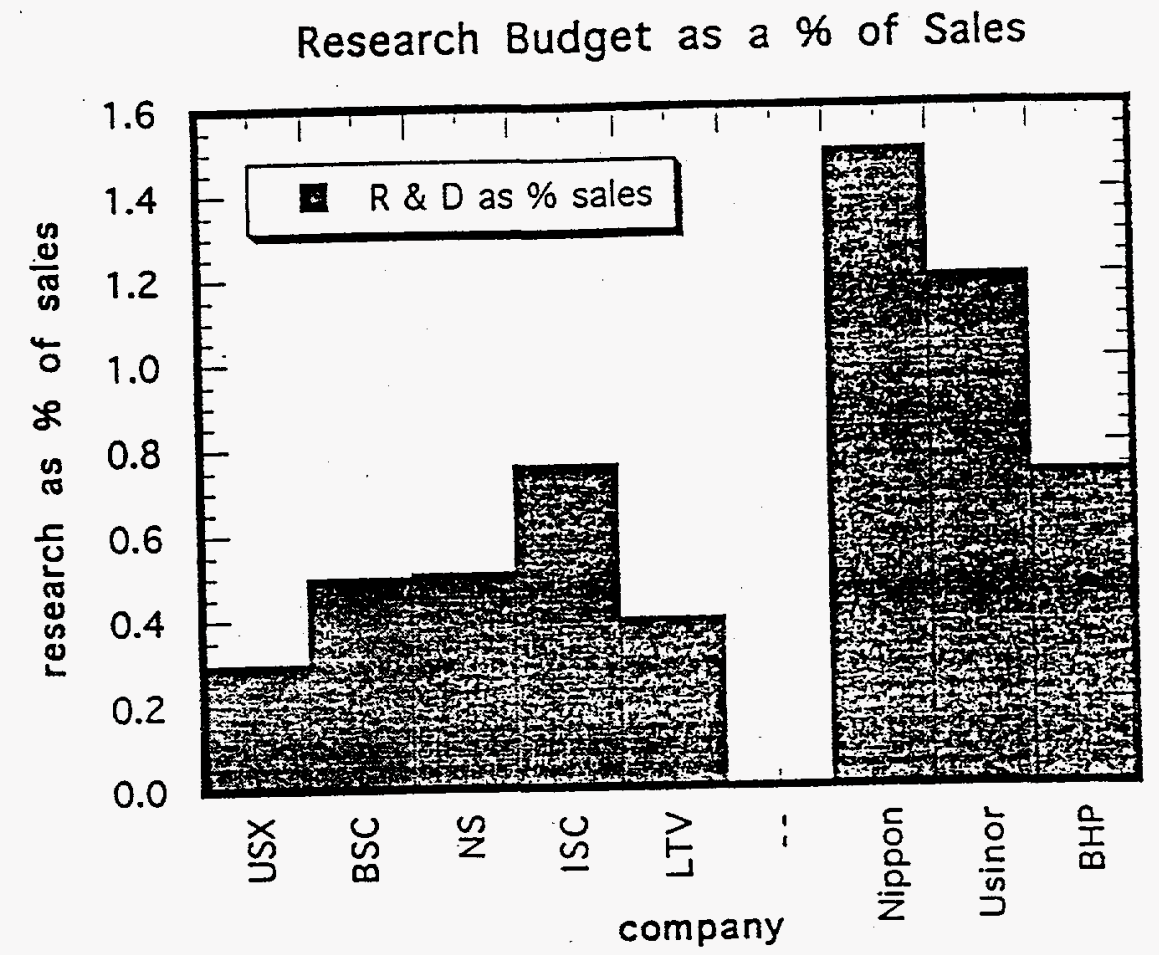

\subsection{7}

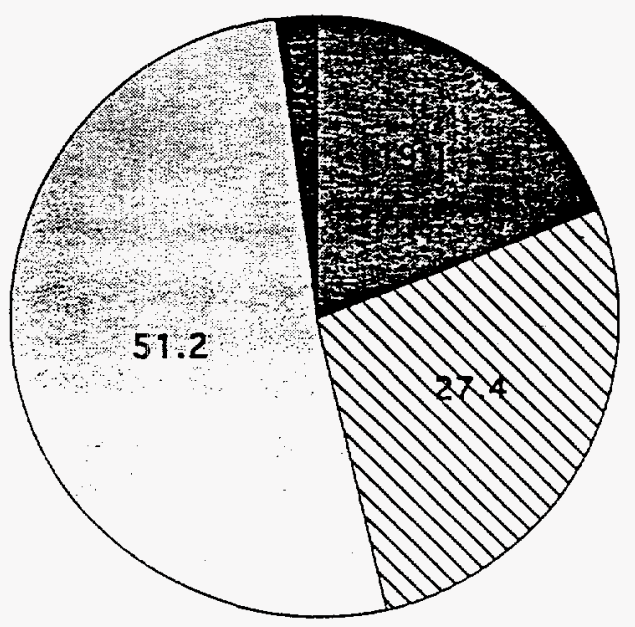

Distribution of R\&D Programs

United States Averages

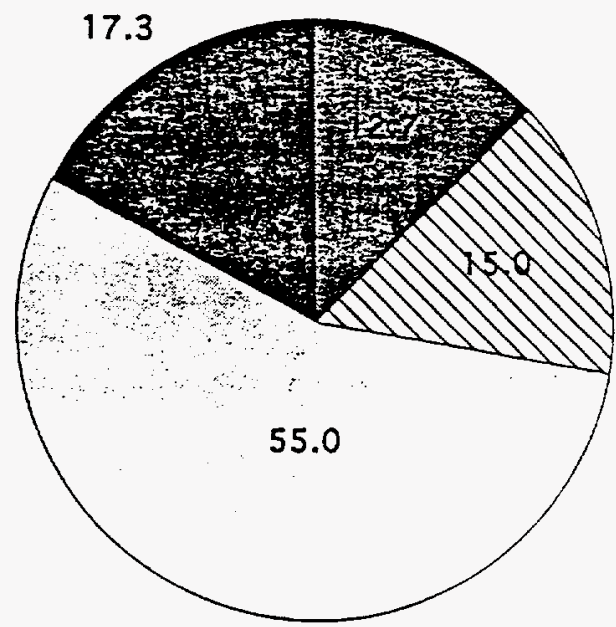

Distribution of R\&D Programs

Selected International Companies 


\section{FUTURE INDUSTRY}

\section{CURRENT RESEARCH AND DEVELOPMENT}

In conclusion, whereas US steel industry research activities have become more responsive and effective, its total capability has been greatly reduced. Much of the precompetitive research activities are most effectively done by collaboration by leveraging research funds and technical skills.

Collaborative and Government Assisted Research and Development: It is beyond the scope of this report to discuss the US industry's collaborative research programs. However, some useful observations are noteworthy.

- The most effective government sponsored research programs are those with substantial industrial involvement and control. Research at government laboratories or universities has added to our basic knowledge but has been rarely effectively commercialized unless there is close interaction with industry.

- In recent years the Department of Energy has stimulated and sponsored effective and potentially critical research and development. These include, but are not limited to, Direct Steelmaking, Waste Recycle, Advanced Control, coal injection trials and work on scrap dezincing. In these programs, DOE has provided support and a framework for collaboration but has not attempted to influence or run the technical programs.

- Other governmental and non-governmental agencies have helped fund and organize collaborative research activities. These include the Center for Materials Production (sponsored by EPRI) and the Gas Research Institute.

- Currently most collaborative research has been organized on an individual project basis with participation on a "opt in" basis. Whereas this has been reasonably effective it may be useful to examine alternative strategies. 


\section{FUTURE INDUSTRY}

\section{CURRENT RESEARCH AND DEVELOPMENT}

- Fundamental collaborative research is primarily done at two NSF Industry/University Cooperative Centers; Center for Iron and Steelmaking Research (CISR) at Carnegie Mellon University and at Steel Research Center (SRC) at Colorado School of Mines. Their programs are designed to be responsive to the industry's long term needs. These two centers receive funding from individual companies with little government support. Some government support is given by the Bureau of Mines to the Pyrometallurgy Center at the University of Missouri but their steel related research is limited and will be phased out soon.

\section{INTERNATIONAL ACTIVITIES}

Major international technological developments are underway which may accelerate the development of the vision and effect the technology requirements for its development.

It is well beyond the scope of this report to review the major technological developments throughout the world. However, there are a few major programs which should be considered

Direct Ironmaking: In addition to the COREX process, which is commercially available, major programs are underway in Japan (DIOS), Australia (HIsmelt), The Netherlands (Hoogoven's Cyclone Converter Process) and France (Usinor Sacilor's Jupiter) for using coal directly to produce hot metal. It is generally assumed that DIOS and HIsmelt are about a year ahead of Direct Steelmaking while the others are behind. Certain aspects of these technologies could be combined into an attractive new process, e.g., the AISI Process with the Cyclone Converter.

Strip Casting: There is a major international effort to develop strip casting. The major developments to date are for stainless and have been reported by Usinor 


\section{FUTURE INDUSTRY}

\section{CURRENT RESEARCH AND DEVELOPMENT}

Sacilor-Thyssen (Myosotes Project), Nippon Steel-Mitsubishi, and Pacific MetalsHitachi Zosen. Recently, Broken Hill Proprietary (BHP)-IHI announced their strip casting process for carbon steels with a machine being constructed to cast strip up to 1.9 meters wide and up to 25 ton coils. In examining the technical needs for the future industry these developments must be considered. It most likely is not the best use of the available resources to attempt to develop a process in competition with those mentioned. Selected US industry resources would be best used to commercialize and optimize these technologies.

Scrap Substitutes: The first iron carbide plant is being built in Trinidad by Nucor. The performance of this plant should be carefully assessed to determine its capabilities and areas where technical improvements are necessary. Lurgi is developing a fluid bed process for the reduction of iron oxide using coal. This has only been tested on a small scale and its development should be monitored.

Recycling: The Japanese Steel Industry, along with Usinor Sacilor, has a major long term project to improve scrap recycling and melting. The project is partially funded by MITI and is called the Shin Seiko or "MEGA" Project. It is funded for seven years at several hundred million dollars. The project is aimed at improving scrap quality by removing residual elements such as copper, zinc, etc. and the development of a fossil fuel or improved electrical based melting technology. The European community has similar type programs.

These are the major international technology thrust areas which will affect our vision and its development. Other development activities, such as improved coal injection in the blast furnace, etc., should also be reviewed before expending resources on similar developments. 


\section{TECHNICAL CHALLENGES AND OPPORTUNITIES}

The vision presented of the future steel industry is realistic and capable of being achieved. However, there are numerous technical challenges which must be overcome for the technologies envisioned to be fully developed and commercialized. These challenges provide opportunities for research and development programs which will be responsive and critical to the future industry. Since "one man's challenge is another man's opportunity" these will be examined together. For convenience they have been grouped into major areas including Ironmaking, Scrap and Scrap Alternatives, etc. Environmental Concerns is a major driver for many of these developments but there are also separate environmental challenges which are listed. In addition, significant general research and development is required for support of the future industry including refractories, oxygen production, sensors, training, basic research, etc. which are grouped under support activities.

It is beyond the scope of the report, or the ability of the authors, to describe specific solutions or research programs. Only general areas of research and development are given. Also, evolutionary incremental developments are not considered unless a series of these will significantly change the technology.

The research, development or commercialization program may be taken on a wide variety of organizations or groups collaboratively. These include individual steel companies, industry support companies, industrial research organizations (AISI, SMA, GRI, CMP, etc.) national laboratories and universities. These programs may be partially funded by various federal and local governmental agencies such as the DOE, EPA, Department of the Interior, etc. However, strong direct industrial involvement is believed to be critical for successful implementation. 


\section{FUTURE INDUSTRY}

CHALLENGES AND OPPORTUNITIES

\section{IRONMAKING}

Direct Ironmaking: One of the major developments required is a coal based and low capital ironmaking process. The process must eliminate cokemaking and eventually agglomeration. Despite the international efforts by AISI, DIOS, and others, many technical improvements are required before commercialization.

- Effective use of volatiles by combustion in the furnace or in other ways.

- Improved metal containment including refractories and innovative concepts such as water cooled systems.

- Improved post combustion to increase productivity and energy efficiency.

- Improved hot metal desulfurization processes to address the higher anticipated sulfur contents.

- Improved injection and material feeding systems to use ores or waste oxides without agglomeration.

- Sensors for foam height measurement and process control.

Blast Furnace Optimization: In the vision of the future industry the conventional blast furnace will continue to produce a significant portion of the iron requirements. Further improvements in the process are possible and several are required.

- Improved and optimum use of hydrocarbon injectants including coal, natural gas, and low cost oil derivatives. This work should address burden preparation and distribution for improved gas flow.

- Recirculation of top gas to optimize the use of injectants and oxygen.

- Improved campaign life including refractories and support systems.

- Improved process models and instrumentation which include the major developments with injectants and recirculation. 


\section{FUTURE INDUSTRY}

\section{CHALLENGES AND OPPORTUNITIES}

- Improved burden materials including low gangue ore, pellets, or sinter.

- A low cost process to produce partially reduced ore, pellets, or sinter which can be used as a feed reducing fuel requirements and increasing productivity.

- Ore injection associated with high coal rates to increase the coke/ore ratio in the burden, which may be required for smooth operation.

Before proceeding with any of the above, a careful economic analysis, including capital, should be performed to be certain the proposed improvement is economic.

Cokemaking: With the vision presented, the blast furnace will continue to play an important role. Whereas the coke requirement will be greatly reduced, roughly $30-60 \%$ of the fuel will be supplied with conventional coke. Whereas no new technology currently appears to address all of the economics and environmental concerns related to cokemaking, new concepts or revisitation of older concepts should not be ruled out.

Revolutionary Processes: Revolutionary concepts should be explored. For example, iron produced by direct reduction with gas or coal being used directly in an oxygen steelmaking type process.

\section{STEELMAKING AND REFINING}

As discussed, steelmaking and refining has fewer critical challenges with regards to the vision of the future industry. However, some areas of development will benefit the industry.

- Improved dynamic process control models using unique sensors.

- Improved refractory systems and practices.

- Use of the $\mathrm{CO}$ from the process by increased post combustion for supplying energy or recapture of the $\mathrm{CO}$ for other purposes. 


\section{FUTURE INDUSTRY}

\section{CHALLENGES AND OPPORTUNITIES}

- Slag free tapping from the BOF to improve steel quality.

- Development of a continuous oxygen steelmaking process with higher productivity and lower capital cost. In particular, continuous charging, continuous tapping, and dynamic control must be developed. A new process should be more flexible with respect to feed materials.

- Ladle processes for reducing nitrogen and phosphorus and less expensive processes for sulfur.

- Development of ladle processes with lower maintenance cost including refractories.

\section{SCRAP AND SCRAP ALTERNATIVES}

Scrap Preparation: Based on the premise that there will be sufficient obsolete low quality scrap but insufficient high quality low residual scrap for the future, programs should be developed to improve scrap quality.

- Develop better physical techniques such as cryogenic fragmentation, magnetic separation, etc. to segregate the portion of scrap high in residual elements. These developments may be more evolutionary than revolutionary and could be done by collaborative efforts between the scrap and steel industry with government stimulating the research program.

- Develop low cost chemical techniques to remove copper, zinc, etc. from scrap. Whereas many techniques have been examined in the past none have proven to be commercially viable. Techniques to be examined or continued include electrochemical dezincing, and removal of copper from solid scrap using high or low temperature dissolution techniques.

- Develop techniques to easily identify materials in scrap. In particular, a method of being $100 \%$ sure there are no radioactive materials in bundled scrap is 


\section{FUTURE INDUSTRY}

\section{CHALLENGES. AND OPPORTUNITIES}

needed.

- Develop techniques to increase the density and melting characteristics of scrap.

- Develop technologies to effectively use or economically dispose of shredder fluff or to use it for valuable purposes.

Scrap Alternatives: For the expansion of scrap based production into higher quality products, and to allow use of more lower quality scrap, the use of scrap alternatives produced from ore will be essential.

- Develop a coal based process for reducing iron ore in the solid state. Technologies such as composite pellets or fluid beds with mixed fluids should be considered.

- Develop technologies to reduce the sulfur content of iron produced in the solid state using coal.

- Even though gaseous reduction processes will not be used significantly in the US, developments which reduce the operating or capital costs or improve the quality of the product would be beneficial to the industry. In particular, low temperature processes such as the production of iron carbide with low discharge to the atmosphere should be considered.

- The direct liquid ironmaking processes discussed previously could also provide high quality feed material to the scrap based processes and should be developed for this purpose.

The incentives to use more obsolete scrap are enormous. The cost of steel production is reduced, the energy required is greatly reduced and the national environment is greatly improved. The US industry and government should consider a project similar to the Japanese initiative 


\section{FUTURE INDUSTRY}

\section{CHALLENGES AND OPPORTUNITIES}

\section{("MEGA" Project). Since scrap recycling is a global concern the industry may wish to explore joint efforts with other countries.}

\section{IMPROVED MELTING PROCESSES}

The future steel vision includes improved revolutionary processes to melt scrap with and without scrap alternatives. The processes will be more flexible energy efficient, have higher productivity, and use a variety of energy sources including electricity, coal, natural gas and energy from other processes. It will be necessary to:

- Improve conventional EAF technology including reduced flicker and improved return electrodes for DC furnaces.

- Develop new scrap preheating technologies which are efficient, compatible with high productivity, and avoid environmental problems such as the formation of dioxins. The processes maybe within the furnace such as a shaft furnace, or EOF, continuous heating, such as Consteel, or an improved system such as a rotary kiln, or an improved batch process.

- Improve post combustion for energy and environmental concerns.

- Develop hybrid or alternative melting technologies which use electrical and fossil fuel (coal or natural gas). The processes should be flexible without conflicting with high productivity operation. Oxygen for combustion may be injected using conventional lances or by bottom injection. Unique methods of introducing the fuel should also be developed.

\section{ELECTRIC FURNACE DUST}

- The most pressing environmental problem facing scrap based production is the disposal or treatment of electric furnace dusts. Technologies should be developed 


\section{FUTURE INDUSTRY}

\section{CHALLENGES AND OPPORTUNITIES}

to minimize dust, segregate dust into high and low zinc fractions to increase its value to a zinc producer or any technology to reduce the overall cost of disposal. The Center for Materials Production with partial DOE funding began a modest program on this problem in late 1994. EAF dust should be viewed as a "man made resource" for iron and zinc production.

\section{SOLIDIFICATION PROCESS}

As discussed earlier, no single casting system will be used for all markets. Improvements can be made in conventional and thin slab casting. A new independent strip casting development should not be undertaken because developments in other countries are too far ahead and near commercialization. However, critical areas. still must be addressed, in particular, edge containment and metal delivery.

\section{Conventional and Thin Slab Casting}

- New mold fluxes without any potential environmental problems.

- Metal delivery systems to the mold which reduce turbulence, slag entrainment and nozzle clogging.

- Minimize surface cracking by process optimization including level control, mold oscillation, air/mist sprays and electromagnetic brakes.

- New sensors to detect slag more precisely.

- Obtain longer casting strings by improved breakout detection, tube changing, refractories and scheduling.

- Expert systems to diagnosis defects and others to reduce maintenance costs.

- Improved models for thin slab casting to predict structure and eventual properties.

\section{Strip Casting}

- Improved edge containment including refractories and electromagnetics. 


\section{FUTURE INDUSTRY}

\section{CHALLENGES AND OPPORTUNITIES}

- Improved metal delivery with improved control and reduced turbulence.

- Improved roll design to reduce dimension and structure variations.

\section{New Processes}

- Flexible processes with respect to slab dimensions.

- Near net shape casting processes for constructional shapes.

\section{FINISHING AND PRODUCTS}

- Hot Rolling Mill: Develop a sensing device to measure actual properties (as opposed to temperature and geometry) during hot rolling to permit on-line control.

- Coiling: Develop procedures and compositions to produce a microstructure which will respond to compact annealing to permit production of adequately formable sheet.

- Pickling: For environmental reasons, develop an acid-free method to remove hot mill scale.

- Annealing: Develop a process which will have a much shorter working length being annealed. Transverse flux induction heating is a process which shows promise in this area.

- Coated products: The use of coatings to provide corrosion protection (tin or various zinc and zinc alloy coatings) or aesthetic appeal (paint, enamel) has grown considerably. There may be opportunities for other coatings or alternate ways of applying current or related coatings.

The quality and value to the customer of all steel products has improved enormously in the last few years in areas which have direct value to the customer. A few examples of this are much better dimensional control leading to weight reduction since designers can be more confident of delivered thicknesses, improved formability giving better part consolidation and lower breakage 


\section{FUTURE INDUSTRY}

\section{CHALLENGES AND OPPORTUNITIES}

in stamping of complex parts, lower energy losses in magnetic steels, and improved cleanliness (lower inclusion content) which affects many areas such as deep drawn cans and the fatigue life of bearing steels.

- While the ability of individual operating units to produce these properties has improved dramatically over the last decade, and there are opportunities for continuing improvement, these could be much smaller (although still useful) than those already achieved. It appears that the most likely source of continuing value will be the cost reductions possible in the minimization of time to reduce the first solid to a finished product ready for shipping. This is already being done for long products and hot rolled. sheet from thin slabs. The more complex issues to produce medium and high quality sheet on a much shorter time cycle will demand research in several areas.

- The desire to couple processes as much as possible to approach continuous flow must recognize that flexibility and opportunities to correct on-line are thereby limited. Thus the ability to measure continuously all the important features such as grain size or yield strength, or to fully understand an adequate surrogate, would be of great value.

- The use of controlled processing on the hot mill runout table has been of great value and is well understood. If a cold mill is coupled directly to a novel annealing process such as transverse flux induction heating, the generation of the very specific microstructures necessary for control of eventual properties will need to be related to the variables available in the processing line (e.g., time-temperature-deformation combinations). This can perhaps be simplified if fewer different compositions were fully characterized to enable control of needed properties more by processing than chemistry. This need will be even more urgent if the hot mill is directly coupled to subsequent processes. 


\section{FUTURE INDUSTRY}

\section{CHALLENGES AND OPPORTUNITIES}

- The practicality of casting directly to sheet may soon be available. For some purposes, this may be adequate as cast or with a minimum of hot deformation to improve the surface to some degree. However, obtaining the properties available in current "cold rolled" sheet is a challenge. It may be that these can not be accomplished and new opportunities to use steel in design must be devised with a different balance between functionality and aesthetics.

To a lesser degree, some of the same problems may arise with the intermediate thickness slabs $(25-100 \mathrm{~mm})$ but the greater thickness allows more opportunity for texture and other necessary structure generation.

\section{ENVIRONMENTAL TECHNOLOGIES}

In addition to the major requirements for increased use of obsolete scrap, the development of a direct ironmaking process, disposal or use of shredder fluff and treatment and decrease of EAF dusts other technical challenges exist.

\section{WASTE MINIMIZATION}

- Processes to use blast furnace and BOF dusts and sludges, mill scale, and possible EAF dusts as a raw material for the production of iron and other metals such as zinc must be developed. The AISI Waste Recycle Process has a high potential as such a process but others exist such as smelting of composite pellets of wastes and coal in a shaft or cupola furnaces.

- Technologies which make more beneficial use of blast furnace, BOF and EAF slags must be developed. This includes their use as an ingredient of building materials such as cement or in the production of mineral wool.

- Slag minimization by the improvement of refining processes should be examined. 


\section{FUTURE INDUSTRY \\ CHALLENGES AND OPPORTUNITIES}

\section{EMISSIONS}

- New technologies for treating large quantities of water used in steelmaking so they can be reused should be developed.

- Development of processes and equipment to reduce emissions, such as VOC and $\mathrm{NO}_{\mathrm{X}}$, from electric furnaces.

- Risk analysis of toxic emissions should be carried out to eliminate some arbitrary conservative assumptions.

- Research is needed to replicate the current studies in the health effects of small particulates. In particular, research is required to determine if there is a threshold and the cost of achieving credible results.

- Technologies to preheat obsolete scrap without the formation of dioxins will be required.

- New technologies for assessing future site clean ups and methods other than the current brute force method of digging up the soil for expensive treatment or disposal.

\section{INDUSTRY SUPPORT REQUIREMENTS}

There are several general areas in which research and development will aid in the successful commercialization of new technologies or optimization of current technologies.

- Since oxygen is required for many new technologies., low cost production of lower purity oxygen or economical compact production will be needed.

- Refractories and general metal and slag containment continues to be a major cost in current processes and an obstacle in new processes. Selected targeted developments in these areas are required.

- Expert systems and advanced computer models and control will be required, in particular, expert systems for maintenance and defect diagnosis. 


\section{FUTURE INDUSTRY}

\section{CHALLENGES AND OPPORTUNITIES}

- Models for global optimization and process linkage.

- Independent energy and environmental life cycle analysis for products and processes.

-While it is beyond the scope of this report, an assessment of education and training needs for the future industry should be made and in particular, improving these areas when new technologies are implemented. 


\section{PRIORITIES AND CONCLUDING REMARKS}

The US steel industry has made tremendous improvements in quality and costs in the past decade and now is the low cost quality producer for its market. The industry is continuing to improve its value to customers to insure that steel is the material of choice for the next century. The industry will develop continuous processes which are more flexible, increase recycling of scrap and in-plant wastes and reduce emissions. The new processes should be targeted to eliminate other process steps, e.g., direct ironmaking eliminates cokemaking and near net shape casting hot rolling. This continued improvement will require the commercialization of several of the generic processes and carrying out many of the research and development programs outlined in this report. Several of the programs and process commercialization will be done by individual companies. However, due to the high cost of development and commercialization and the lack of technical resources many will be done on a collaborative basis.

Based on input from the industry, and our own conclusions, the general priority areas for development have been identified.

- Commercialize a direct ironmaking process which uses coal directly and eliminates the capital and environmental concerns with the existing process.

- Commercialize economic processes to recycle in-plant solid wastes, in particular EAF, BOF and blast furnace dusts and sludges.

- Develop processes to upgrade charge materials to the EAF, in particular improving scrap quality by reducing residuals and developing a coal based direct reduction process.

- Develop steelmaking processes which are more flexible with respect to charge materials (hot metal, scrap and DRI) and energy sources (fossil fuel and electric) and combine effective scrap preheating. 


\section{PRIÓRITIES AND CONCLUDING REMARKS}

- Develop processes in series to approach continuous flow and carryout global optimization of the entire steelmaking system to reduce costs, energy and production times.

- Work on improvements to current rolling equipment and to sensors and process control to produce continuing viable improvements in property combinations to keep steels competitive and cost-effective.

- Further improvements in coating technology, and its control, to tailor products to applications.

- A continuing emphasis on customer anticipation and satisfaction, ranging from development of realistic simulated service tests to cooperation in developing customer-specific opportunities in forming and joining. 